Article

\title{
Evaluation of Broadband and Narrowband Vegetation Indices for the Identification of Archaeological Crop Marks
}

\author{
Athos Agapiou *, Diofantos G. Hadjimitsis and Dimitrios D. Alexakis \\ Department of Civil Engineering and Geomatics, Cyprus University of Technology, Remote Sensing \\ Laboratory, Saripolou 2-8, 3603 Limassol, Cyprus; E-Mails: d.hadjimitsis@cut.ac.cy (D.G.H.); \\ dimitrios.alexakis@cut.ac.cy (D.D.A.) \\ * Author to whom correspondence should be addressed; E-Mail: athos.agapiou@cut.ac.cy; \\ Tel.: +357-2500-2471; Fax: +357-2500-2661.
}

Received: 15 October 2012; in revised form: 3 December 2012 / Accepted: 5 December 2012 / Published: 7 December 2012

\begin{abstract}
Several studies in the past have examined the spectral capability of multispectral and hyperspectral imagery for the identification of crop marks, while recent studies have applied different vegetation indices in order to support remote sensing archaeological applications. However, the use of vegetation indices for the detection of crop marks lacks in accuracy assessment and critical evaluation. In this study, 71 vegetation indices were indexed, from the relevant bibliography, and evaluated for their potential to detect such crop marks. During this study, several ground spectroradiometric campaigns took place, in a controlled archaeological environment in Cyprus, cultivated with barley crops, during a complete phenological cycle (2011-2012). All vegetation indices, both broadband and narrowband, were evaluated for their separability performance, and the results were presented through tables and diagrams. In the end, the use of more than one vegetation index is suggested in order to enhance the final results. In fact, several not widely used vegetation indices are suggested and evaluated using both Landsat TM and EO-1 Hyperion images.
\end{abstract}

Keywords: vegetation indices; remote sensing archaeology; ground spectroscopy; crop marks; Alampra test field

\section{Introduction}

Vegetation Indices (VIs) have been widely used for supporting archaeological investigations [1-5]. Some studies aim at monitoring archaeological sites and monuments using satellite images [6,7], while 
some other studies are focused on the detection of buried archaeological relics (i.e., crop marks) [8-11]. The latest have been used in archaeology since the first grayscale aerial images were available to researches. Crop marks are usually formed in areas where vegetation overlays near-surface archaeological remains. In this case, archaeological features can retain soil moisture with a different percentage of moisture compared to non-archaeological areas [12].

VIs intend to explore vegetation's spectral signature characteristics, both in the visible and near-infrared part of the spectrum. Vegetation stress associated with sub-surface soil disturbance may be observed from visual symptoms, such as stunted growth and sparse vegetation cover [13]. Moreover, as [14] argue, canopy reflectance in the visible and near infrared is strongly dependent on both structural (i.e., amount of leaves per area, leaf orientation, canopy structure) and biochemical properties (i.e., chlorophylls, carotenoids) of the canopy. Hence, it is very difficult to develop a "unique" VI exclusively sensitive to one plant variable. Methods for extraction information from hyperspectral data related to vegetation characteristics have been discussed in detail [15]. Indeed, the use of hyperspectral data for monitoring vegetation characteristics is increasingly needed in order to characterize, model, classify and map agricultural crops and natural vegetation, specifically in the study in [16].

VIs can be either retrieved using multispectral or hyperspectral satellite images. Moreover, airborne sensors are also used to support archaeological investigations (e.g., [17]). Nevertheless, as the study in [14] has shown, airborne and satellite reflectance signals may be additionally influenced by soil, illumination, atmospheric conditions and the sensor observation geometry [18]. Recently, [2,7] have demonstrated that ground spectroscopy can also be used for the retrieval of vegetation characteristics. In this case, several errors can be minimized, since the measurements are taken from a close distance from the canopy, while at the same time, calibrated Lambertian panels are being used (see [19]). As [16] highlighted, the advances of hyperspectral sensors have contributed to the study of spectral signatures in controlled environments.

As [20] argue, a growing number of studies have focused on evaluating spectral indices in terms of their sensitivity to vegetation biophysical parameters, as well as to external factors affecting canopy reflectance. Despite the fact that several indices exist in the literature-both broadband and narrowband - only a small number of these indices are practically used or evaluated for remote sensing archaeology applications. The Normalized Differential Vegetation Index (NDVI) is considered to be the most widely used index for archaeological studies (e.g., [1-3]).

This study aims to analyze the performance of several indices, both broadband and narrowband, that can be used for archaeological investigations. More than seventy different VIs were evaluated (71 in total) and tested for their performance during the detection of archaeological crop marks. The equations of these indices are presented in a fully updated table (Table 1). For the needs of the study, several ground spectroradiometric data retrieved from a "controlled archaeological area" were used. These ground data were extracted during a whole phenological cycle of the barley crops (2011-2012) in the study area of Alampra, Cyprus.

\section{Vegetation Indices}

Several vegetation indices have been presented in the relevant literature. In their study, [21] have reported that more than fifty different remote sensing VIVIs have been used in the literature since 1995. 
However, since then, especially after the deployment of hyperspectral sensors, several other VIs have been developed (see, for instance, Table 1). Indeed, the use of hyperspectral data has significantly contributed to the further study of vegetation characteristics. Hyperspectral data may be used in order to remove highly correlated bands, to create physically meaningful VIs, to create new VIs not sampled by broad bands and, moreover, to create multi-linear indices (i.e., indices involving more than two bands) [16].

As [14] report, VIs can be divided into five main categories according to their formula (equation) or according to the potential use of each index: (a) broadband indices that use broadband reflectance; (b) narrowband indices that use narrowband reflectance (hyperspectral); (c) leaf pigment indices that were developed in order to examine several pigments in the leaf (e.g., Cl-a etc.); (d) stress indices, which were developed for monitoring stress conditions in the canopy; and (e) water stress indices. Moreover, [22] report that narrowband VIs can be divided into three main categories: (a) structure; (b) biochemistry; and (c) plant physiology/stress. However, VIs can be simply divided according to the wavelength characteristics used in their formula (broadband and narrowband indices).

Table 1 provides the list of all VIs used in this study (71 different indices). It should be noted that all indices mentioned in Table 1 have a range from 400 up to $1,050 \mathrm{~nm}$, since this was the spectral range of the ground spectroradiometer used in order to collect the ground measurements (see next Chapter). Due to the numerous indices used in this study, only the formula is shown in Table 1. Additional details for the development and the characteristics of each index can be found in the relative reference shown in Table. 1.

As it is shown in the following table, similar broadband and narrowband indices exist in the literature (e.g., NDVI, SR, etc.). Furthermore, the same narrowband vegetation index can be found several times in the literature with a slightly different wavelength (e.g., see SR1-SR5). Moreover, some other indices might be modifications of other known indices (e.g., Modified Simple Ratio, Modified Triangular Vegetation Index, etc.). The majority of indices shown in Table 1 tend to explore the red and near infrared part of the spectrum, while some others may use either blue or green wavelengths (e.g., SARVI, Greenness Index). The variability of these VIs shows that each VI was initially developed in order to enhance a specific canopy reflectance parameter or to minimize atmospheric errors, soil background scattering, etc.

Table 1. Vegetation indices used for the aims of the study (both broadband and narrowband).

\begin{tabular}{|c|c|c|c|}
\hline No & Vegetation Index & Equation & Reference \\
\hline \multicolumn{4}{|c|}{ Broadband Vegetation Indices } \\
\hline 1 & EVI (Enhanced Vegetation Index) & $2.5\left(\mathrm{p}_{\mathrm{NIR}}-\mathrm{p}_{\mathrm{red}}\right) /\left(\mathrm{p}_{\mathrm{NIR}}+6 \mathrm{p}_{\mathrm{red}}-7.5 \mathrm{p}_{\text {blue }}+1\right)$ & [23] \\
\hline 2 & $\begin{array}{l}\text { Green NDVI (Green Normalized Difference Vegetation } \\
\text { Index) }\end{array}$ & $\left(p_{N I R}-p_{\text {green }}\right) /\left(p_{N I R}+p_{\text {green }}\right)$ & [24] \\
\hline 3 & NDVI (Normalized Difference Vegetation Index) & $\left(\mathrm{p}_{\mathrm{NIR}}-\mathrm{p}_{\mathrm{red}}\right) /\left(\mathrm{p}_{\mathrm{NIR}}+\mathrm{p}_{\mathrm{red}}\right)$ & [25] \\
\hline 4 & SR (Simple Ration) & $\mathrm{p}_{\mathrm{NIR}} / \mathrm{p}_{\mathrm{red}}$ & {$[26]$} \\
\hline 5 & MSR (Modified Simple Ratio) & $\mathrm{p}_{\mathrm{red}} /\left(\mathrm{p}_{\mathrm{NIR}} / \mathrm{p}_{\mathrm{red}}+1\right)^{0.5}$ & [27] \\
\hline 6 & MTVI2 (Modified Triangular Vegetation Index) & $\begin{array}{l}{\left[1.5\left(1.2 *\left(p_{\mathrm{NIR}}-\mathrm{p}_{\text {green }}\right)-2.5\left(\mathrm{p}_{\mathrm{Red}}-\mathrm{p}_{\text {green }}\right)\right] /\left[\left(2 \mathrm{p}_{\mathrm{NIR}}+1\right)^{2}-\left(6 \mathrm{p}_{\mathrm{NIR}}-5 \mathrm{p}_{\mathrm{Red}}^{0.5}\right)\right.\right.} \\
-0.5]^{0.5}\end{array}$ & [28] \\
\hline 7 & $\begin{array}{l}\text { RDVI (Renormalized Difference } \\
\text { Vegetation Index) }\end{array}$ & $\left(p_{\mathrm{NIR}}-\mathrm{p}_{\mathrm{red}}\right) /\left(\mathrm{p}_{\mathrm{NIR}}+\mathrm{p}_{\mathrm{red}}\right)^{1 / 2}$ & [29] \\
\hline
\end{tabular}


Table 1. Cont.

\begin{tabular}{|c|c|c|c|}
\hline No & Vegetation Index & Equation & Reference \\
\hline \multicolumn{4}{|c|}{ Broadband Vegetation Indices } \\
\hline 8 & IRG (Red Green Ratio Index) & $\mathrm{p}_{\text {Red }}-\mathrm{p}_{\text {green }}$ & [30] \\
\hline 9 & PVI (Perpendicular Vegetation Index) & $\begin{array}{l}\left(\mathrm{p}_{\mathrm{NIR}}-\alpha \mathrm{p}_{\mathrm{red}}-\mathrm{b}\right) /\left(1+\alpha^{2}\right) \\
\mathrm{p}_{\mathrm{NIR}, \text { soil }}=\alpha \mathrm{p}_{\mathrm{red}, \text { soil }}+\mathrm{b}\end{array}$ & [31] \\
\hline 10 & RVI (Ratio Vegetation Index) & $\mathrm{p}_{\mathrm{red}} \mathrm{p}_{\mathrm{NIR}}$ & [32] \\
\hline 11 & TSAVI (Transformed Soil Adjusted Vegetation Index) & $\begin{array}{l}{\left[\alpha\left(\mathrm{p}_{\mathrm{NIR}}-\alpha \mathrm{p}_{\mathrm{NIR}}-\mathrm{b}\right)\right] /\left[\left(\mathrm{p}_{\mathrm{red}}+\alpha \mathrm{p}_{\mathrm{NIR}}-\alpha \mathrm{b}+0.08\left(1+\alpha^{2}\right)\right)\right]} \\
\mathrm{p}_{\mathrm{NIR}, \text { soil }}=\alpha \mathrm{p}_{\mathrm{red}, \text { soil }}+\mathrm{b}\end{array}$ & [33] \\
\hline 12 & MSAVI (Modified Soil Adjusted Vegetation Index) & {$\left[2 \mathrm{p}_{\mathrm{NIR}}+1-\left[\left(2 \mathrm{p}_{\mathrm{NIR}}+1\right)^{2}-8\left(\mathrm{p}_{\mathrm{NIR}}-\mathrm{p}_{\mathrm{red}}\right)\right]^{1 / 2}\right] / 2$} & [34] \\
\hline 13 & ARVI (Atmospherically Resistant Vegetation Index) & $\begin{array}{l}\left(\mathrm{p}_{\mathrm{NIR}}-\mathrm{p}_{\mathrm{rb}}\right) /\left(\mathrm{p}_{\mathrm{NIR}}+\mathrm{p}_{\mathrm{rb}}\right) \\
\mathrm{p}_{\mathrm{rb}}=\mathrm{p}_{\mathrm{red}}-\gamma\left(\mathrm{p}_{\text {blue }}-\mathrm{p}_{\mathrm{red}}\right)\end{array}$ & {$[35]$} \\
\hline 14 & GEMI (Global Environment Monitoring Index) & $\begin{array}{l}\mathrm{n}(1-0.25 \mathrm{n})\left(\mathrm{p}_{\mathrm{red}}-0.125\right) /\left(1-\mathrm{p}_{\mathrm{red}}\right) \\
\mathrm{n}=\left[2\left(\mathrm{p}_{\mathrm{NIR}}{ }^{2}-\mathrm{p}_{\mathrm{red}}{ }^{2}\right)+1.5 \mathrm{p}_{\mathrm{NIR}}+0.5 \mathrm{p}_{\mathrm{red}}\right] /\left(\mathrm{p}_{\mathrm{NIR}}+\mathrm{p}_{\mathrm{red}}+0.5\right)\end{array}$ & {$[36]$} \\
\hline 15 & SARVI (Soil and Atmospherically Resistant Vegetation Index) & $\begin{array}{l}(1+0.5)\left(\mathrm{p}_{\mathrm{NIR}}-\mathrm{p}_{\mathrm{rb}}\right) /\left(\mathrm{p}_{\mathrm{NIR}}+\mathrm{p}_{\mathrm{rb}}+0.5\right) \\
\mathrm{p}_{\mathrm{rb}}=\mathrm{p}_{\mathrm{red}}-\gamma\left(\mathrm{p}_{\text {blue }}-\mathrm{p}_{\mathrm{red}}\right)\end{array}$ & {$[35]$} \\
\hline 16 & OSAVI (Optimized Soil Adjusted Vegetation Index) & $\left(p_{\mathrm{NIR}}-\mathrm{p}_{\mathrm{red}}\right) /\left(\mathrm{p}_{\mathrm{NIR}}+\mathrm{p}_{\mathrm{red}}+0.16\right)$ & [37] \\
\hline 17 & DVI (Difference Vegetation Index) & $\mathrm{p}_{\mathrm{NIR}}-\mathrm{p}_{\mathrm{red}}$ & [38] \\
\hline 18 & SR $\times$ NDVI (Simple Ratio x Normalized Difference Vegetation Index & $\left(\mathrm{p}_{\mathrm{NIR}}^{2}-\mathrm{p}_{\mathrm{red}}\right) /\left(\mathrm{p}_{\mathrm{NIR}}+\mathrm{p}_{\mathrm{red}}^{2}\right)$ & [39] \\
\hline \multicolumn{4}{|c|}{ Narrowband Vegetation Indices } \\
\hline 19 & CARI (Chlorophyll Absorption Ratio Index) & $\begin{array}{l}\mathrm{p}_{700} \mid \alpha_{670}+\mathrm{p}_{670}+\mathrm{b} / /\left[\mathrm{p}_{670}\left(\alpha^{2}+1\right)^{0.5}\right. \\
\alpha=\left(\mathrm{p}_{700}-\mathrm{p}_{550}\right) / 150 \\
\mathrm{~b}=\mathrm{p}_{550}-550 \alpha\end{array}$ & [40] \\
\hline 20 & GI (Greenness Index) & $\mathrm{p}_{554} / \mathrm{p}_{677}$ & [41] \\
\hline 21 & GVI (Greenness Vegetation Index) & $\left(\mathrm{p}_{682}-\mathrm{p}_{553}\right) /\left(\mathrm{p}_{682}+\mathrm{p}_{553}\right)$ & [42] \\
\hline 22 & MCARI (Modified Chlorophyll Absorption Ratio Index) & {$\left[\left(\mathrm{P}_{700}-\mathrm{P}_{670}\right)-0.2\left(\mathrm{P}_{700}-\mathrm{P}_{550}\right)\right]\left(\mathrm{P}_{700} / \mathrm{P}_{670}\right)$} & [43] \\
\hline 23 & MCARI $_{2}$ (Modified Chlorophyll Absorption Ratio Index) & $1.2\left[2.5\left(\mathrm{p}_{800}-\mathrm{p}_{670}\right)-1.3\left(\mathrm{p}_{800}-\mathrm{p}_{550}\right)\right]$ & [28] \\
\hline 24 & mNDVI (Modified Normalized Difference Vegetation Index) & $\left(\mathrm{p}_{800}-\mathrm{p}_{680}\right) /\left(\mathrm{p}_{800}+\mathrm{p}_{680}-2 \mathrm{p}_{445}\right)$ & [44] \\
\hline 25 & $\mathrm{SR}_{705}$ (Simple Ratio, Estimation of chlorophyll content) & $\mathrm{p}_{750} / \mathrm{p}_{705}$ & [45] \\
\hline 26 & $\mathrm{mNDVI}_{2}$ (Modified Normalized Difference Vegetation Index) & $\left(\mathrm{p}_{750}-\mathrm{p}_{705}\right) /\left(\mathrm{p}_{750}+\mathrm{p}_{705}-2 \mathrm{p}_{445}\right)$ & [44] \\
\hline 27 & MSAVI (Improved Soil Adjusted Vegetation Index) & {$\left[2 \mathrm{p}_{800}+1-\left[\left(2 \mathrm{p}_{800}+1\right)^{2}-8\left(\mathrm{p}_{800}-\mathrm{p}_{670}\right)\right]^{1 / 2}\right] / 2$} & [34] \\
\hline 28 & mSR (Modified Simple Ratio) & $\left(\mathrm{p}_{800}-\mathrm{p}_{445}\right) /\left(\mathrm{p}_{680}-\mathrm{p}_{445}\right)$ & [44] \\
\hline 29 & $\mathrm{mSR}_{2}$ (Modified Simple Ratio) & $\left(\mathrm{p}_{800}-\mathrm{p}_{445}\right) /\left(\mathrm{p}_{680}-\mathrm{p}_{445}\right)$ & [44] \\
\hline 30 & $\mathrm{mSR}_{3}$ (Modified Simple Ratio) & $\left(\mathrm{p}_{800} / \mathrm{p}_{670}-1\right) /\left(\mathrm{p}_{800} / \mathrm{p}_{670}+1\right)^{0.5}$ & {$[46]$} \\
\hline 31 & MTCI (MERIS Terrestrial Chlorophyll index) & $\left(\mathrm{p}_{754}-\mathrm{p}_{709}\right) /\left(\mathrm{p}_{709}-\mathrm{p}_{681}\right)$ & [47] \\
\hline 32 & mTVI (modified Triangular Vegetation Index) & $1.2\left[1.2\left(\mathrm{p}_{800}-\mathrm{p}_{550}\right)-2.5\left(\mathrm{p}_{670}-\mathrm{p}_{550}\right)\right]$ & [28] \\
\hline 33 & NDVI (Normalized Difference Vegetation Index) & $\left(\mathrm{p}_{800}-\mathrm{p}_{670}\right) /\left(\mathrm{p}_{800}+\mathrm{p}_{670}\right)$ & [25] \\
\hline 34 & $\mathrm{NDVI}_{2}$ (Normalized Difference Vegetation Index) & $\left(\mathrm{p}_{750}-\mathrm{p}_{705}\right) /\left(\mathrm{p}_{750}+\mathrm{p}_{705}\right)$ & [48] \\
\hline 35 & OSAVI (Optimized Soil Adjusted Vegetation Index) & $1.16\left(\mathrm{p}_{800}-\mathrm{p}_{670}\right) /\left(\mathrm{p}_{800}+\mathrm{p}_{670}+0.16\right)$ & [37] \\
\hline 36 & RDVI (Renormalized Difference Vegetation Index) & $\left(\mathrm{p}_{800}-\mathrm{p}_{670}\right) /\left(\mathrm{p}_{800}+\mathrm{p}_{670}\right)^{0.5}$ & [49] \\
\hline 37 & REP(Red-Edge Position) & $700+40\left[\left(\mathrm{p}_{670}+\mathrm{p}_{780}\right) / 2-\mathrm{p}_{700}\right] /\left(\mathrm{p}_{740}-\mathrm{p}_{700}\right)$ & {$[50]$} \\
\hline 38 & SIPI (Structure Insensitive Pigment Index) & $\left(\mathrm{p}_{800}-\mathrm{p}_{450}\right) /\left(\mathrm{p}_{800}-\mathrm{p}_{650}\right)$ & [51] \\
\hline 39 & $\mathrm{SIPI}_{2}$ (Structure Insensitive Pigment Index) & $\left(\mathrm{p}_{800}-\mathrm{p}_{440}\right) /\left(\mathrm{p}_{800}-\mathrm{p}_{680}\right)$ & {$[51]$} \\
\hline 40 & $\mathrm{SIPI}_{3}($ Structure Insensitive Pigment Index) & $\left(\mathrm{p}_{800}-\mathrm{p}_{445}\right) /\left(\mathrm{p}_{800}-\mathrm{p}_{680}\right)$ & [52] \\
\hline 41 & SPVI (Spectral polygon vegetation index) & $0.4\left[3.7\left(\mathrm{p}_{800}-\mathrm{p}_{670}\right)-1.2\left|\mathrm{p}_{530}-\mathrm{p}_{670}\right|\right]$ & {$[53]$} \\
\hline
\end{tabular}


Table 1. Cont.

\begin{tabular}{|c|c|c|c|}
\hline No & Vegetation Index & Equation & Reference \\
\hline \multicolumn{4}{|c|}{ Narrowband Vegetation Indices } \\
\hline 42 & SR (Simple Ratio) & $\mathrm{p}_{800} / \mathrm{p}_{680}$ & [26] \\
\hline 43 & $\mathrm{SR}_{1}$ (Simple Ratio) & $\mathrm{p}_{750} / \mathrm{p}_{700}$ & [54] \\
\hline 44 & $\mathrm{SR}_{2}$ (Simple Ratio) & $\mathrm{p}_{752} / \mathrm{p}_{690}$ & [54] \\
\hline 45 & $\mathrm{SR}_{3}$ (Simple Ratio) & $\mathrm{p}_{750} / \mathrm{p}_{550}$ & [54] \\
\hline 46 & $\mathrm{SR}_{4}$ (Simple Ratio) & $\mathrm{p}_{672} / \mathrm{p}_{550}$ & [55] \\
\hline 47 & TCARI (Transformed Chlorophyll Absorption Ratio Index) & $3\left[\left(\mathrm{p}_{700}-\mathrm{p}_{670}\right)-0.2\left(\mathrm{p}_{700}-\mathrm{p}_{550}\right)\left(\mathrm{p}_{700} / \mathrm{p}_{670}\right)\right]$ & {$[56]$} \\
\hline 48 & TSAVI (Transformed Soil Adjusted Vegetation Index) & $\begin{array}{l}{\left[\alpha\left(p_{875}-\alpha p_{680}-b\right)\right] /\left[\left(p_{680}+\alpha p_{875}-\alpha b+0.08\left(1+\alpha^{2}\right)\right)\right]} \\
\alpha=1,062 \\
b=0.022\end{array}$ & {$[37]$} \\
\hline 49 & TVI (Triangular Vegetation Index) & $0.5\left[120\left(\mathrm{p}_{750}-\mathrm{p}_{550}\right)-200\left(\mathrm{p}_{670}-\mathrm{p}_{550}\right)\right]$ & {$[57]$} \\
\hline 50 & VOG (Vogelmann Indices) & $\mathrm{p}_{740} / \mathrm{p}_{720}$ & [58] \\
\hline 51 & $\mathrm{VOG}_{2}$ (Vogelmann Indices) & $\left(\mathrm{p}_{734}-\mathrm{p}_{747}\right) /\left(\mathrm{p}_{715}+\mathrm{p}_{726}\right)$ & [59] \\
\hline 52 & ARI (Anthocyanin Reflectance Index ) & $\left(1 / \mathrm{p}_{550}\right)-\left(1 / \mathrm{p}_{700}\right)$ & {$[60]$} \\
\hline 53 & $\mathrm{ARI}_{2}$ (Anthocyanin Reflectance Index 2) & $\mathrm{p}_{800}\left(1 / \mathrm{p}_{550}\right)-\left(1 / \mathrm{p}_{700}\right)$ & {$[60]$} \\
\hline 54 & BGI (Blue Green Pigment Index) & $\mathrm{p}_{450} \mathrm{p}_{550}$ & {$[61]$} \\
\hline 55 & BRI (Blue Red Pigment Index) & $\mathrm{p}_{450} / \mathrm{p}_{690}$ & [61] \\
\hline 56 & CRI (Carotenoid Reflectance Index) & $\left(1 / \mathrm{p}_{510}\right)-\left(1 / \mathrm{p}_{550}\right)$ & [62] \\
\hline 57 & RGI (Red/Green Index) & $\mathrm{p}_{690} / \mathrm{p}_{550}$ & [61] \\
\hline 58 & CI (Curvature Index) & $\mathrm{p}_{675} \cdot \mathrm{p}_{690} / \mathrm{p}_{683}^{2}$ & [59] \\
\hline 59 & LIC (Curvature Index) & $\mathrm{p}_{440} / \mathrm{p}_{690}$ & [63] \\
\hline 60 & NPCI (Normalized Pigment Chlorophyll index) & $\left(\mathrm{p}_{680}-\mathrm{p}_{430}\right) /\left(\mathrm{p}_{680}+\mathrm{p}_{430}\right)$ & [64] \\
\hline 61 & NPQI (Normalized Phaeophytinization Index) & $\left(\mathrm{p}_{415}-\mathrm{p}_{435}\right) /\left(\mathrm{p}_{415}+\mathrm{p}_{435}\right)$ & [65] \\
\hline 62 & PRI (Photochemical Reflectance Index) & $\left(\mathrm{p}_{531}-\mathrm{p}_{570}\right) /\left(\mathrm{p}_{531}+\mathrm{p}_{570}\right)$ & [66] \\
\hline 63 & $\mathrm{PRI}_{2}$ (Photochemical Reflectance Index) & $\left(\mathrm{p}_{570}-\mathrm{p}_{539}\right) /\left(\mathrm{p}_{570}+\mathrm{p}_{539}\right)$ & [67] \\
\hline 64 & PSRI (Plant Senescence Reflectance Index) & $\left(\mathrm{p}_{680}-\mathrm{p}_{500}\right) / \mathrm{p}_{750}$ & [68] \\
\hline 65 & $\mathrm{SR}_{5}$ (Simple Ratio) & $\mathrm{p}_{690} / \mathrm{p}_{655}$ & [59] \\
\hline 66 & $\mathrm{SR}_{6}($ Simple Ratio $)$ & $\mathrm{P}_{685} / \mathrm{p}_{655}$ & [59] \\
\hline 67 & VS (Vegetation Stress ratio) & $\mathrm{P}_{725} / \mathrm{p}_{702}$ & [13] \\
\hline 68 & MVSR (Modified Vegetation Stress ratio) & $\mathrm{P}_{723} / \mathrm{p}_{700}$ & [13] \\
\hline 69 & fWBI (floating Water Band Index) & $\mathrm{p}_{900} / \min \mathrm{p}_{920-980}$ & [69] \\
\hline 70 & WI (Water Index) & $\mathrm{p}_{900} / \mathrm{p}_{970}$ & {$[69]$} \\
\hline 71 & SG (Sum Green Index) & mean of reflectance across the $500 \mathrm{~nm}$ to $600 \mathrm{~nm}$ & {$[30]$} \\
\hline
\end{tabular}

\section{Case Study Area and Ground Measurements}

A controlled archaeological site was developed in the Alampra village, located in central Cyprus (WGS 84, 36o N: 535051, 3870818). In this field, a $5 \times 5 \mathrm{~m}$ square was constructed in order to simulate ancient "tombs" at a depth of $25 \mathrm{~cm}$ (Figure 1) [70,71]. During the construction of the controlled field, particular attention was paid to maintain the original stratigraphy of the soil (i.e., the original ground surface was placed at the top). Moreover, the creation of the "tomb" aimed to create a 
trapped underground gas pocket. Since the whole area was then cultivated similarly with barley crop, Global Position Systems (GPS) were used in order to trace the "tombs".

Figure 1. (a) Photo from the construction of the controlled archaeological environment located at the Alampra village. (b) The area was then cultivated with barley crops. (c) Photo of the barley crop during its full growth. The linear crop marks formed in the area above the archaeological environment is shown with an arrow.

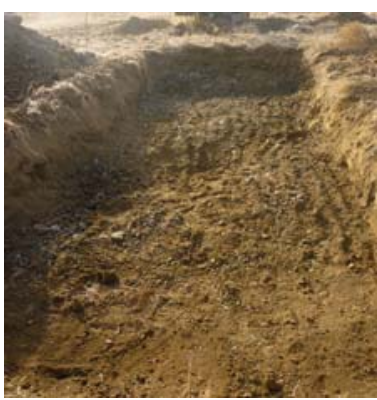

(a)

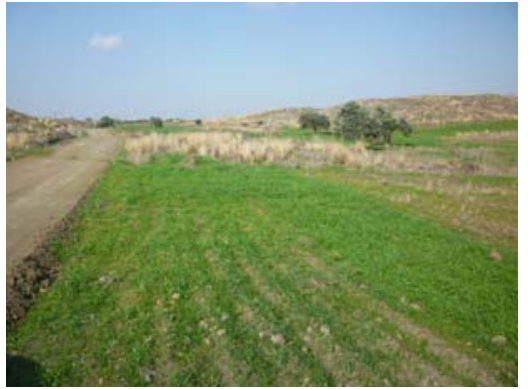

(b)

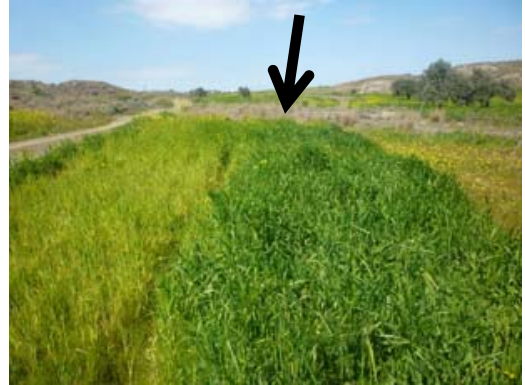

(c)

During the phenological cycle of the crops (2011-2012), more than sixteen (16) in situ spectroradiometric campaigns took place in the study area. In detail, the dates for these cloud-free campaigns were: (1): 10/17/2011, (2): 10/26/2011, (3): 10/31/2011, (4): 11/9/2011, (5): 11/16/2011, (6): 11/23/2011, (7): 11/28/2011, (8): 12/13/2011, (9): 12/20/2011, (10): 1/3/2012, (11): 2/11/2012, (12): 2/21/2012, (13): 3/4/2012, (14): 3/17/2012, (15): 3/29/2012 and (16): 4/17/2012.

Figure 2. (a) The ground spectroradiometer GER 1500 used in order to collect the spectral signatures from the "archaeological" and non-archaeological area. (b) The calibrated spectralon panel.

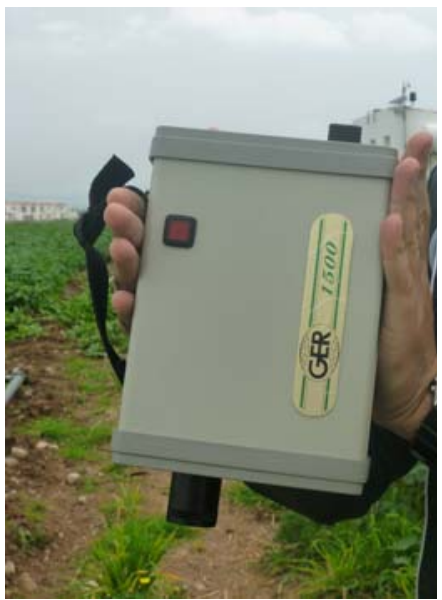

(a)

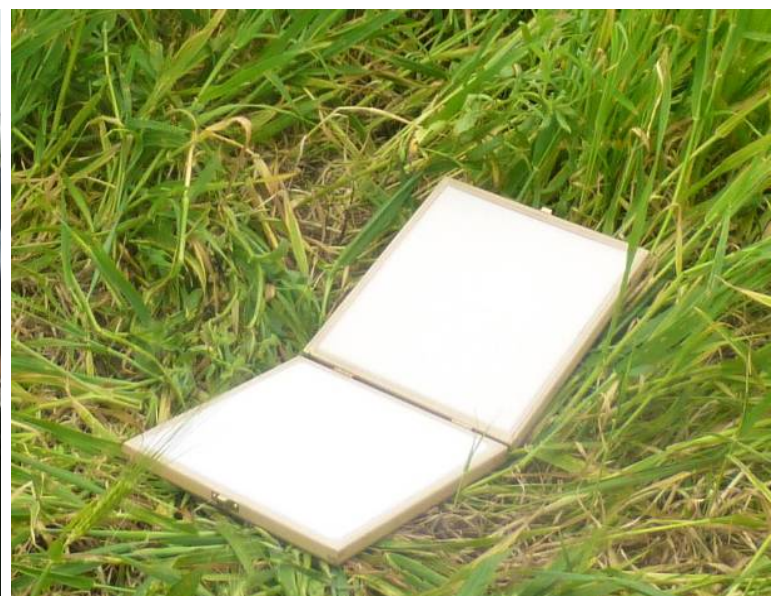

(b)

In each campaign, several ground spectroradiometric measurements were taken over the "archaeological" area and also to the non-archaeological area. For this purpose, a calibrated GER 1500 handheld spectroradiometer was used (Figure 2(a)). This instrument has the ability to record electromagnetic radiation from visible to near infrared spectrum (400-1,050 nm) using 512 different channels with a range of $\sim 1.5 \mathrm{~nm}$. Moreover, a calibrated Lambertian spectralon panel was used 
(Figure 2(b)) in order to measure the incoming solar radiation and calibrate all the measurements taken over the crops. The field of view (FOV) of the instrument was set to 4 degrees $\left(\approx 0.02 \mathrm{~m}^{2}\right.$ from a height of $1.2 \mathrm{~m}$ ). Initially, the incoming radiance was calculated based on the reference measurement at the spectralon panel, while the following measurements were taken over the area of interest (either the archaeological or non archaeological area) (Figure 3).

Altogether, more than 1,600 ground spectroradiometric measurements were taken during the whole phenological cycle of the crops $(\approx 800$ measurements over the "archaeological" area and $\approx 800$ measurements over the non archaeological" area). All these measurements were used in order to assess the performance of VIs.

Figure 3. Methodology followed for the acquisition of ground spectroradiometric measurements. First, (left) the incoming radiance is estimated based on the reference measurement at a calibrated spectralon panel, and then, (right) the reflected radiance from the crops ("archaeological" and non archaeological areas) is also recorded.

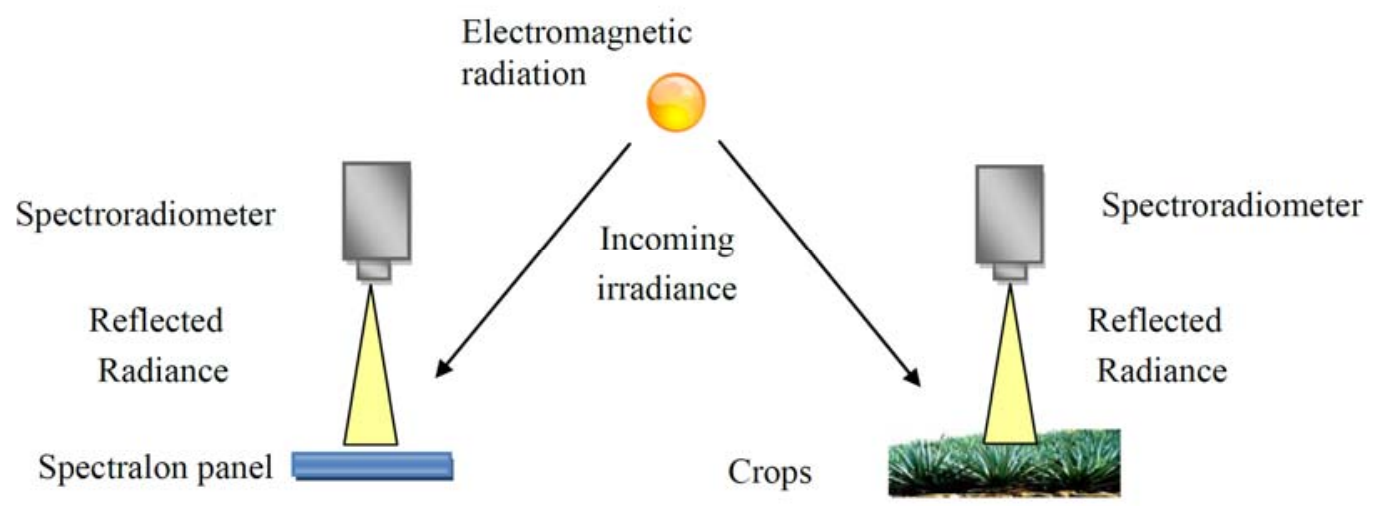

\section{Methodology}

In order to examine the use of broadband vegetation indices, as indicated in Table 1, it is essential to recalculate the ground hyperspectral measurements according to the spectral characteristics of a specific satellite sensor. For this purpose, the authors decided to simulate these data with Landsat TM /ETM+ satellite imagery based on its Relative Spectral Response (RSR) filters. RSR filters describe the instrument relative sensitivity to radiance at various parts of the electromagnetic spectrum [72]. These spectral responses have a value of 0 to 1 and unit-less, since they are relative to the peak response (see Figure 4). Bandpass filters are used in the same way in spectroradiometers in order to transmit a certain wavelength band and to block others [73]. The reflectance from the spectroradiometer was calculated based on the wavelength of each sensor and the RSR filter as follows:

$$
\left[\mathrm{R}_{\text {band }}=\Sigma(\mathrm{Ri} * \mathrm{RSRi}) / \Sigma \mathrm{RSRi}\right]
$$

where:

$\mathrm{R}_{\text {band }}=$ reflectance at a range of wavelength (e.g., Band 1);

$\mathrm{Ri}=$ reflectance at a specific wavelength (e.g., R $450 \mathrm{~nm}$ );

$\mathrm{RSRi}=$ Relative Response value at the specific wavelength . 
Figure 4. Relative Response filters for Bands 1-4 of Landsat TM sensor [72].

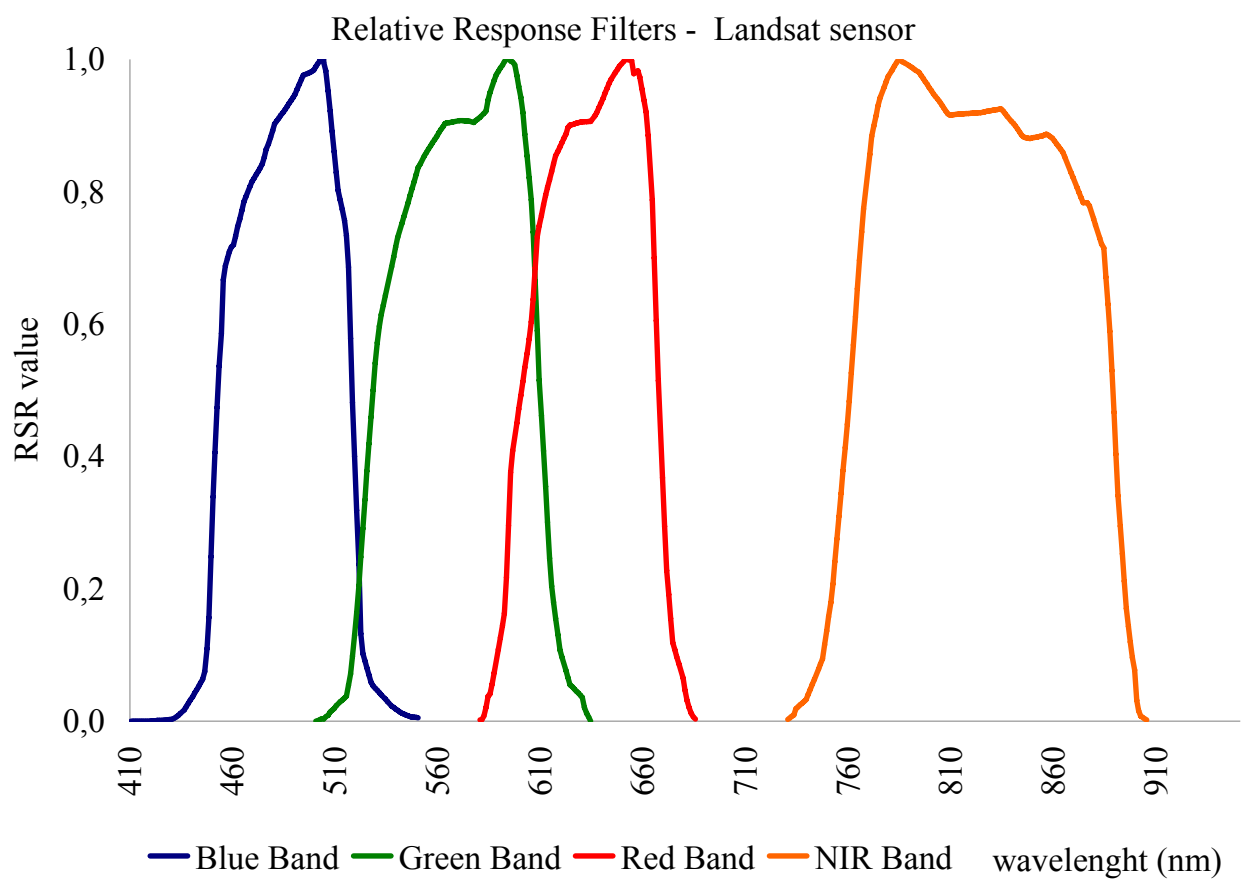

For narrowband Vis, the initial hyperspectral measurements taken from the GER 1500 were used, while for the broadband Vis, the measurements were re-calculated as described above. The performance of each index was examined in comparison to the other indices. The difference in values that occurred from the barley crops over the "tomb" and from the surrounding area was also calculated ("archaeological" and non archaeological area).

\section{Results}

\subsection{Phenological Cycle Diagrams Based on VIs}

Figures 5 and 6 demonstrate the results of several broadband and narrowband VIs, respectively, applied to the barley crops over the "archaeological" (blue line) and non-archaeological area (red line). The standard deviation of the measurements for each field campaign is also demonstrated. X-axes indicate the number of each campaign (see Section 2 for dates), while Y-axes indicate the corresponding VI values (dimensionless). As it is shown in all diagrams, similar VI values are observed for both areas (archaeological and non-archaeological) at the beginning of the phenological cycle (no. 1-6 at X-axes). During this period, the crops have not yet grown, and therefore, these values refer only to soil. Additionally, the standard deviation of the measurement is considered to be relatively low.

After the first rains in the area (no. 7-9 at X-axes). a dramatic increase-or decrease-in the VI values is recorded. During this period, vegetation indices are quite similar for both areas ("archaeological" and non-archaeological). Therefore, VIs cannot be successfully evaluated for the detection of crop marks using remote sensing data, since a significant difference is not expected. However, the following period is according to the diagrams of Figures 5 and 6 , the most promising one for monitoring crop marks by using remote sensing techniques (no. 10-14 at X-axes). VI value over 
"archaeological" area is quite different from the relative measurement over the non-archaeological area. Indeed, measurements over the "tomb" tend to give higher values of VIs ("positive crop marks") with a great statistical difference (t-test). Despite the fact that the standard deviation of these measurements is maximized in this period, a clear difference is recorded. The last two field campaigns (no. 15-16 at X-axes) were made before the harvesting period, when the crops are not photosynthesizing.

Therefore, it is clear from these diagrams that VI values differ from one phenological stage to another. Although the same dataset was used for all these indices, each VI has its own unique phenological diagram. Therefore, the use of more than one VI for the detection of crop marks is suggested in order to enhance the final results.

Figure 5. Broadband vegetation indices during barley crop phenological cycle (2011-2012). Healthy vegetation is indicated with a red line, while vegetation over archaeological remains is indicated with a blue line. (a): EVI, (b): Green NDVI, (c): NDVI, (d): SR, (e): MSR, (f): MTVI2, (g): RDVI, (h): IRG, (i): PVI, (j): RVI, (k): TSAVI, (l): MSAVI, $(\mathbf{m})$ : ARVI, (n): GEMI, (o): OSAVI, (p): DVI and (q): SARVI. No. of field campaign (for dates of measurement, see Section 3) is shown in X-axes, while vegetation indices values are shown in Y-axes. Dashed lines are the standard deviation errors.

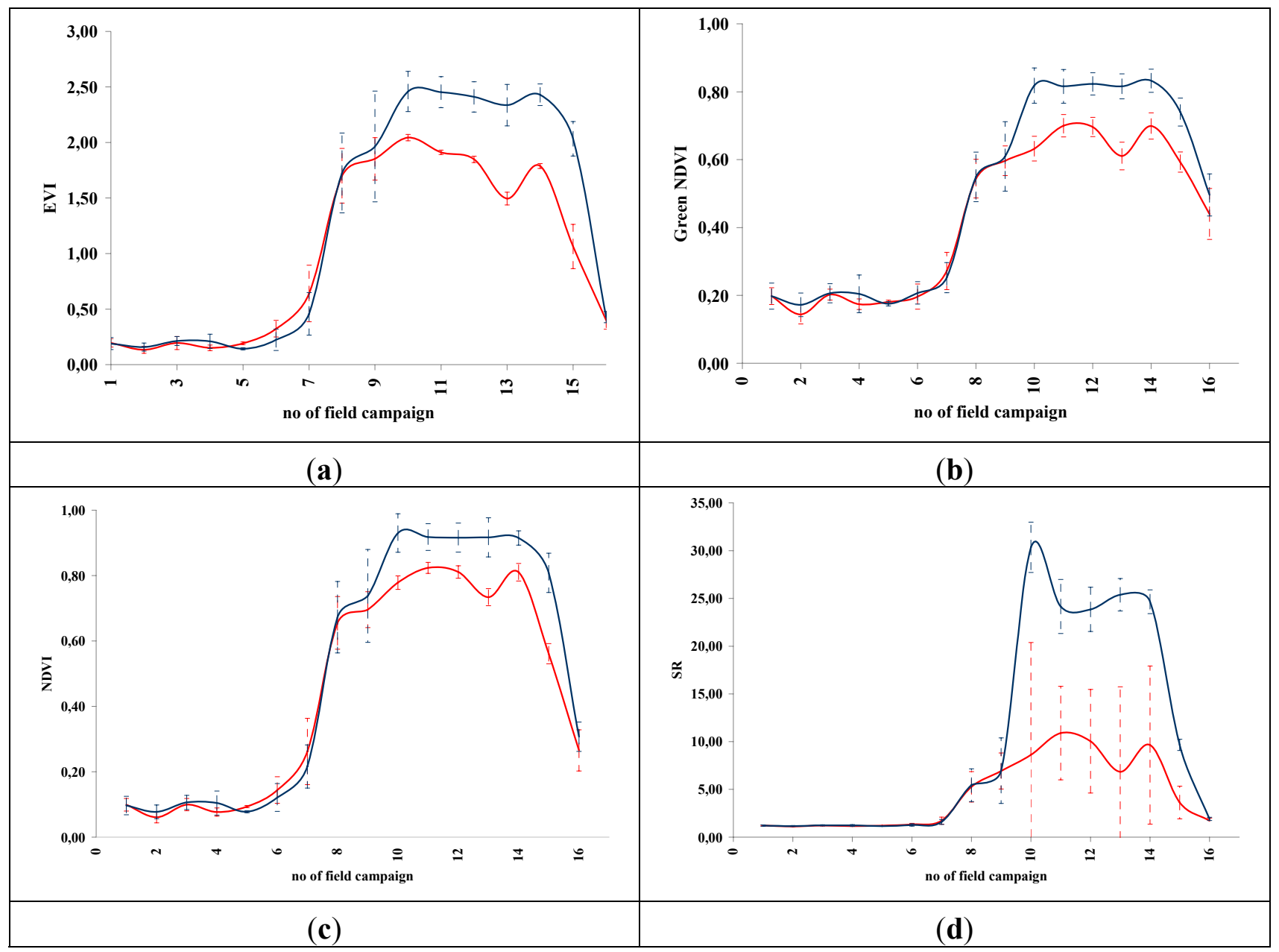


Figure 5. Cont.

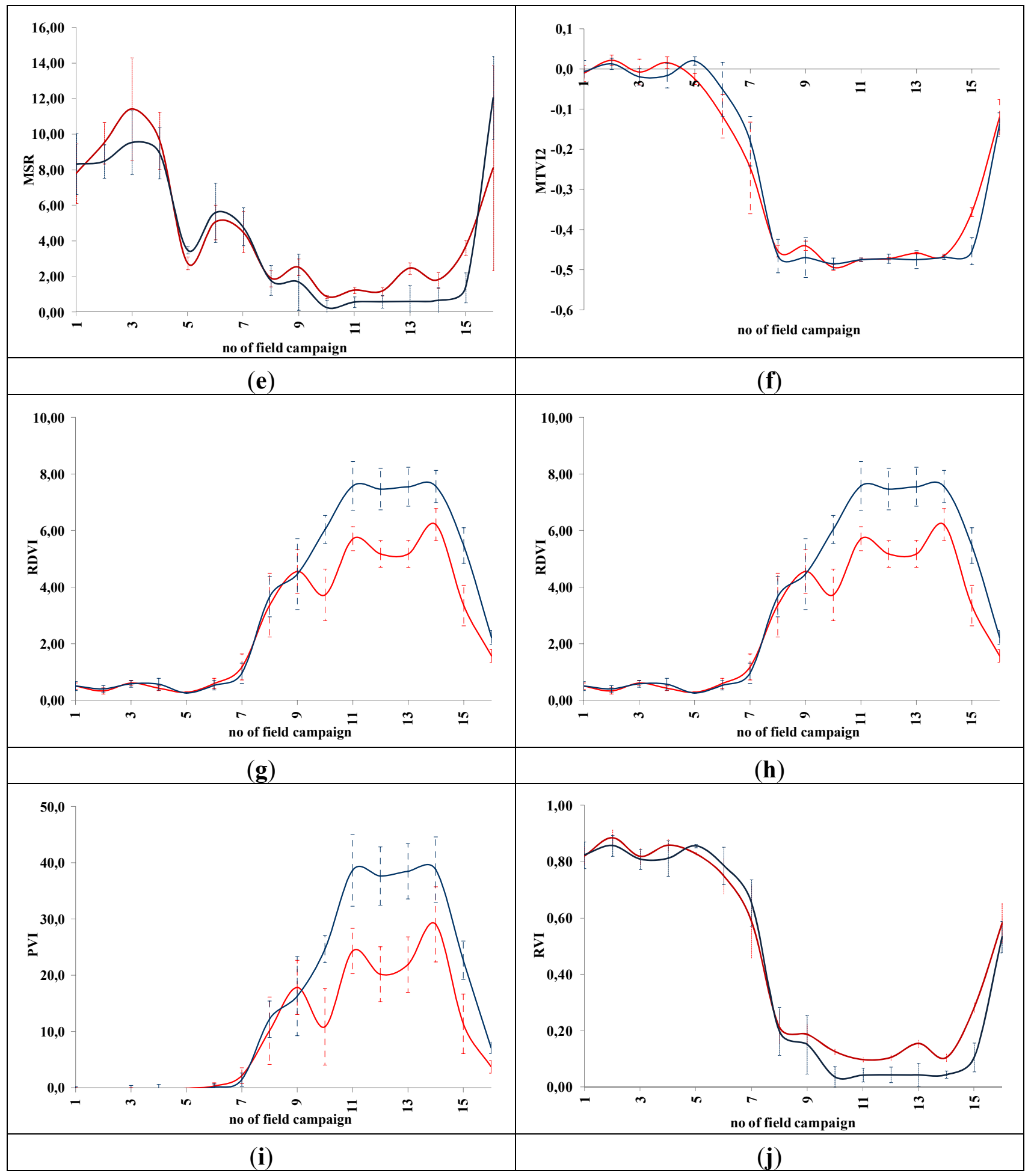


Figure 5. Cont.

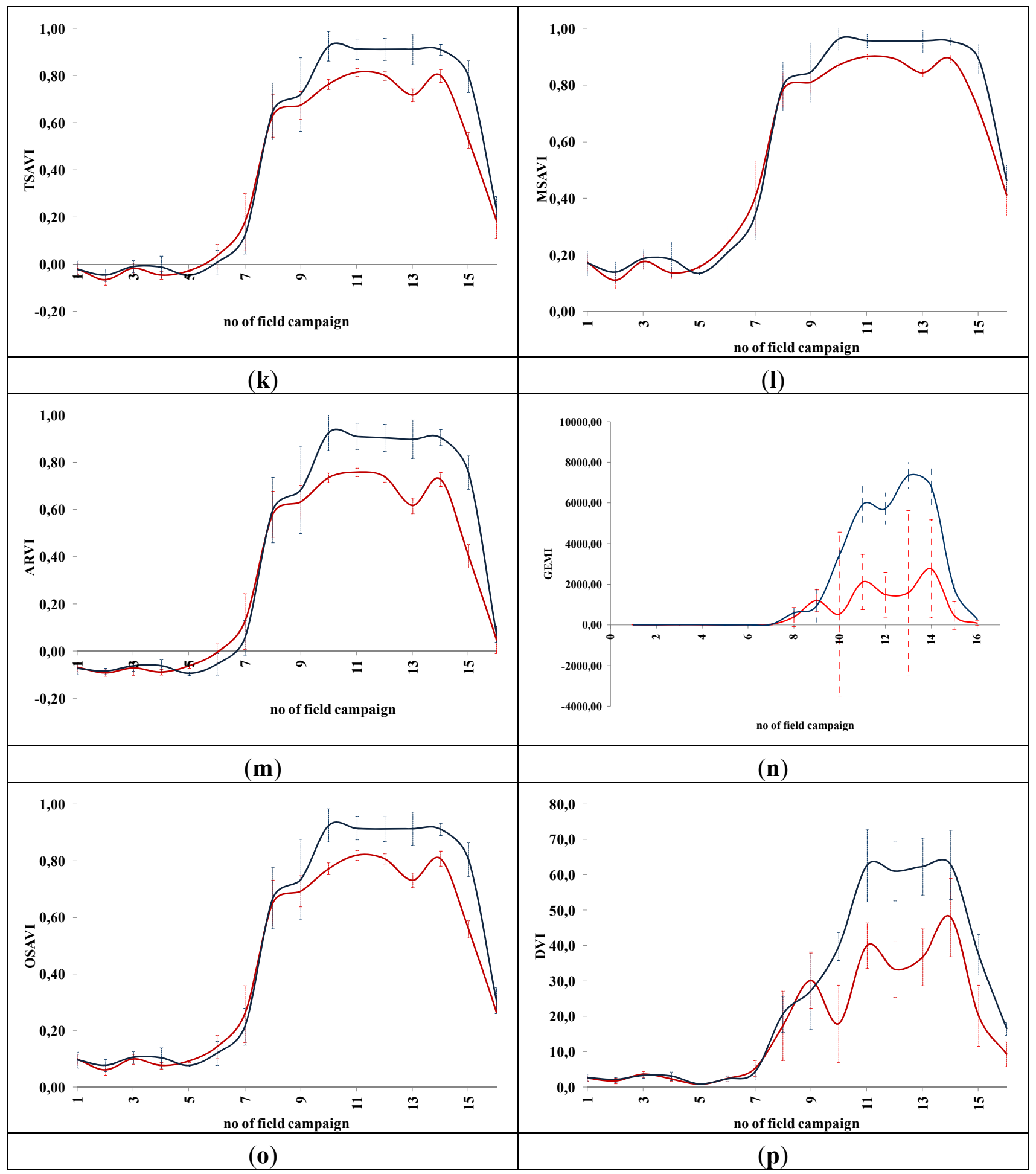


Figure 5. Cont.

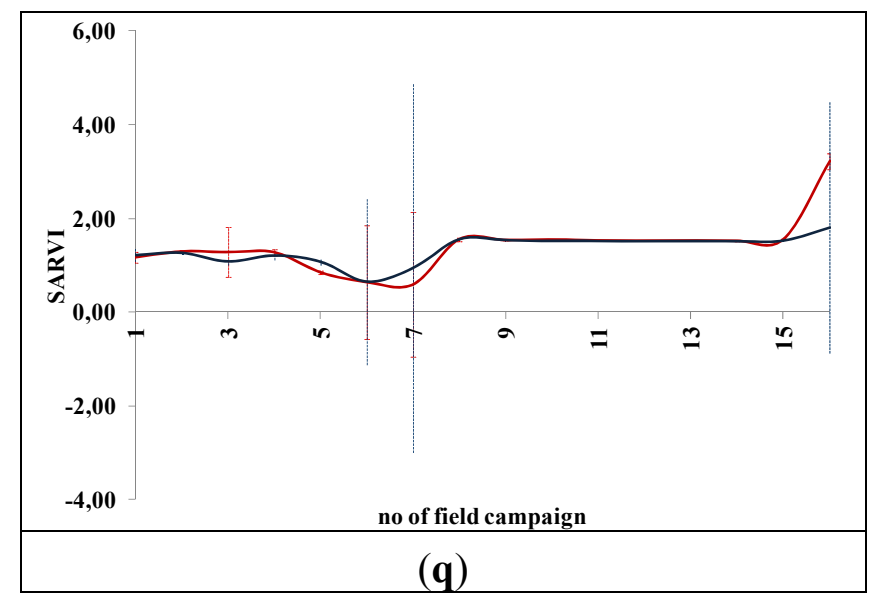

Figure 6. Hyperspectral vegetation indices during the barley crops phenological cycle (2011-2012). Healthy vegetation is indicated with a blue line, while vegetation over archaeological remains is indicated with a red line. (a): CARI, (b): GVI, (c) MCARI, (d): mNDVI, (e): SR705, (f): MSAVI, (g): mSR2, (h): MTCI, (i): mTVI, (j): NDVI, (k): NDVI2, (l): REP, (m): SPVI, (n): SR, (o): SR1, (p): TSAVI, (q): VOG, (r): ARI, (s): BRI, (t): LIC, (u): fWBI and (v): WI. No. of field campaign (for dates of measurement, see section 3) is shown in $\mathrm{X}$-axes, while vegetation indices values are shown in $\mathrm{Y}$-axes. Dashed lines are the standard deviation errors.

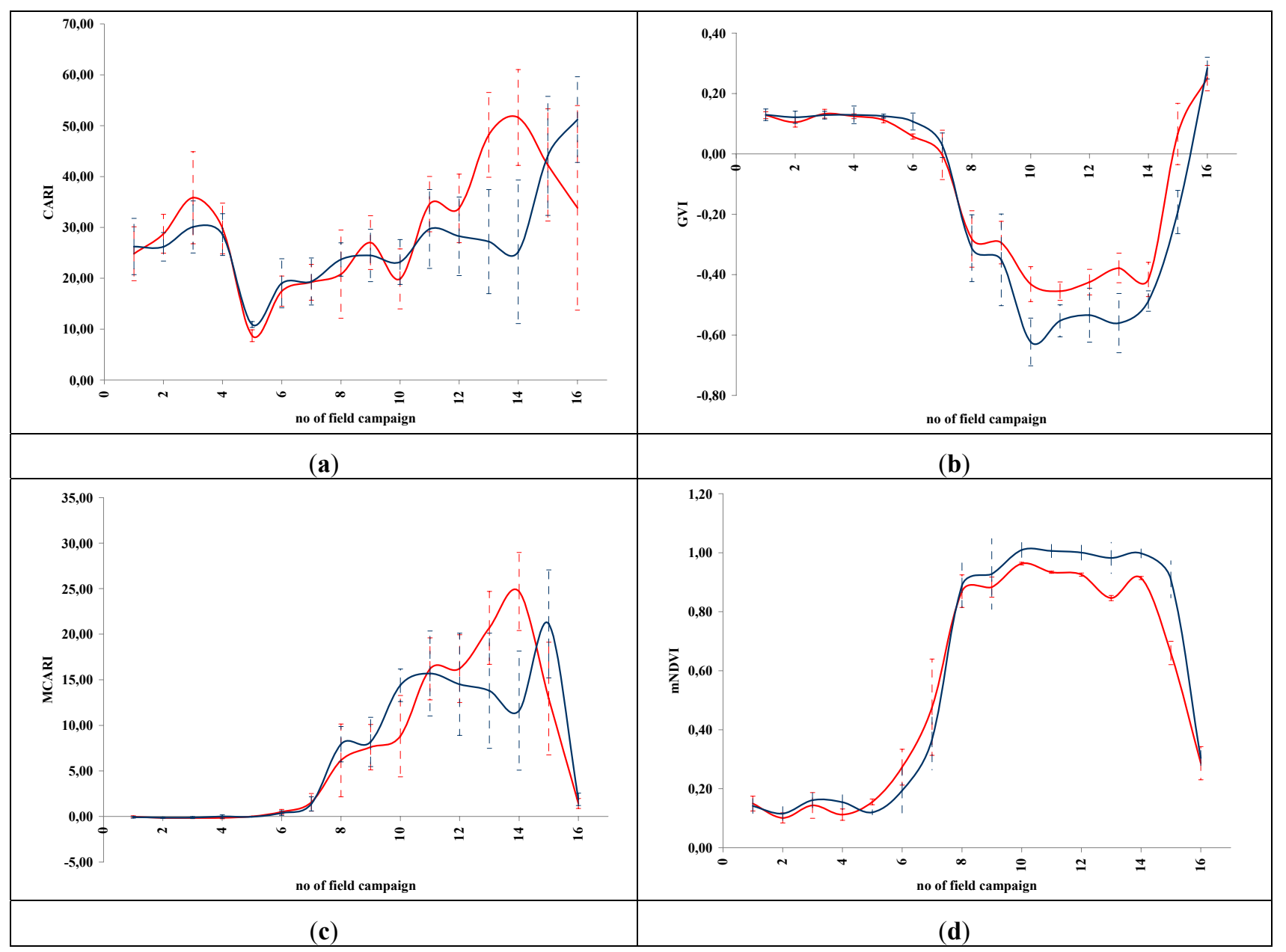


Figure 6. Cont.

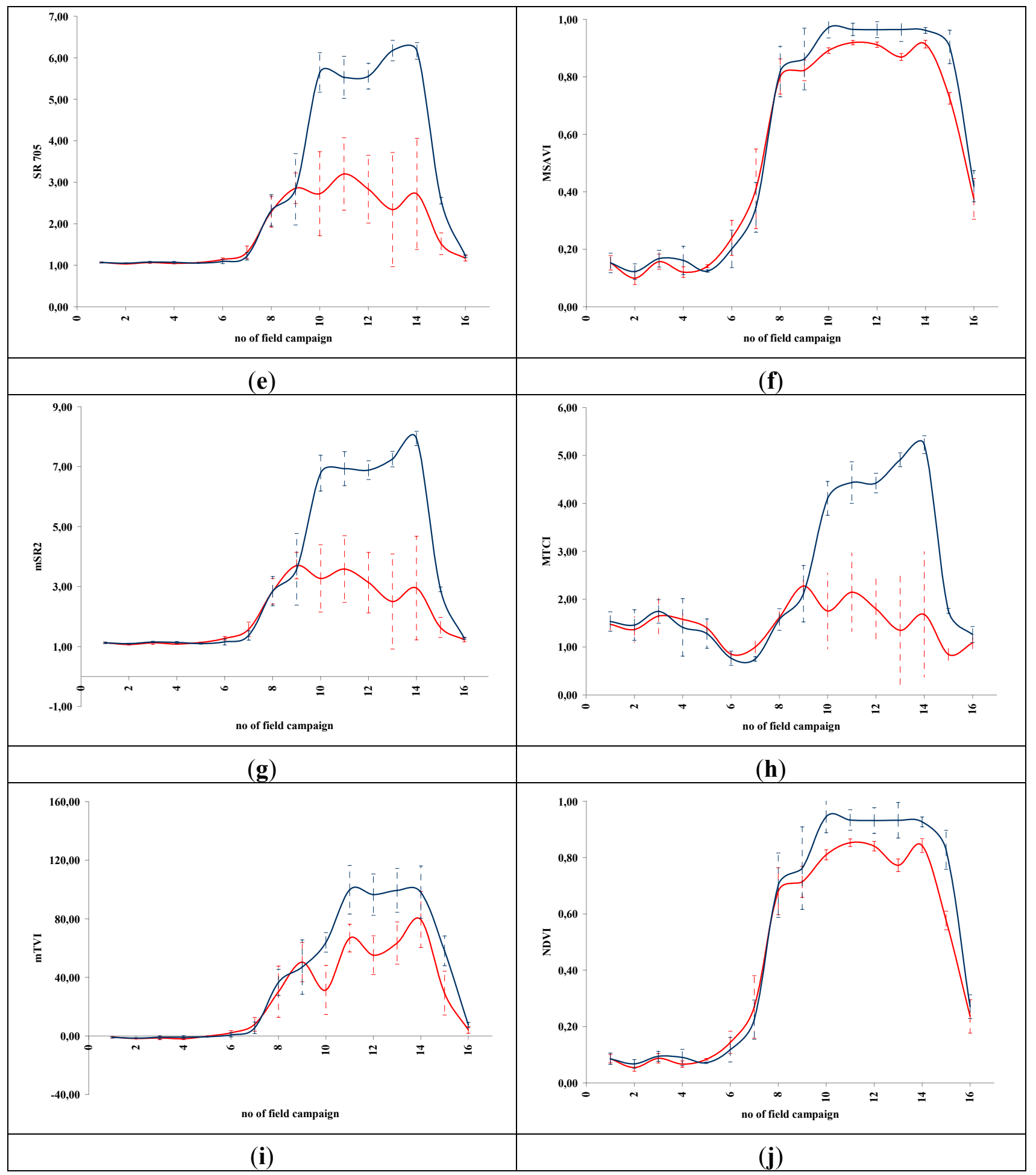


Figure 6. Cont.

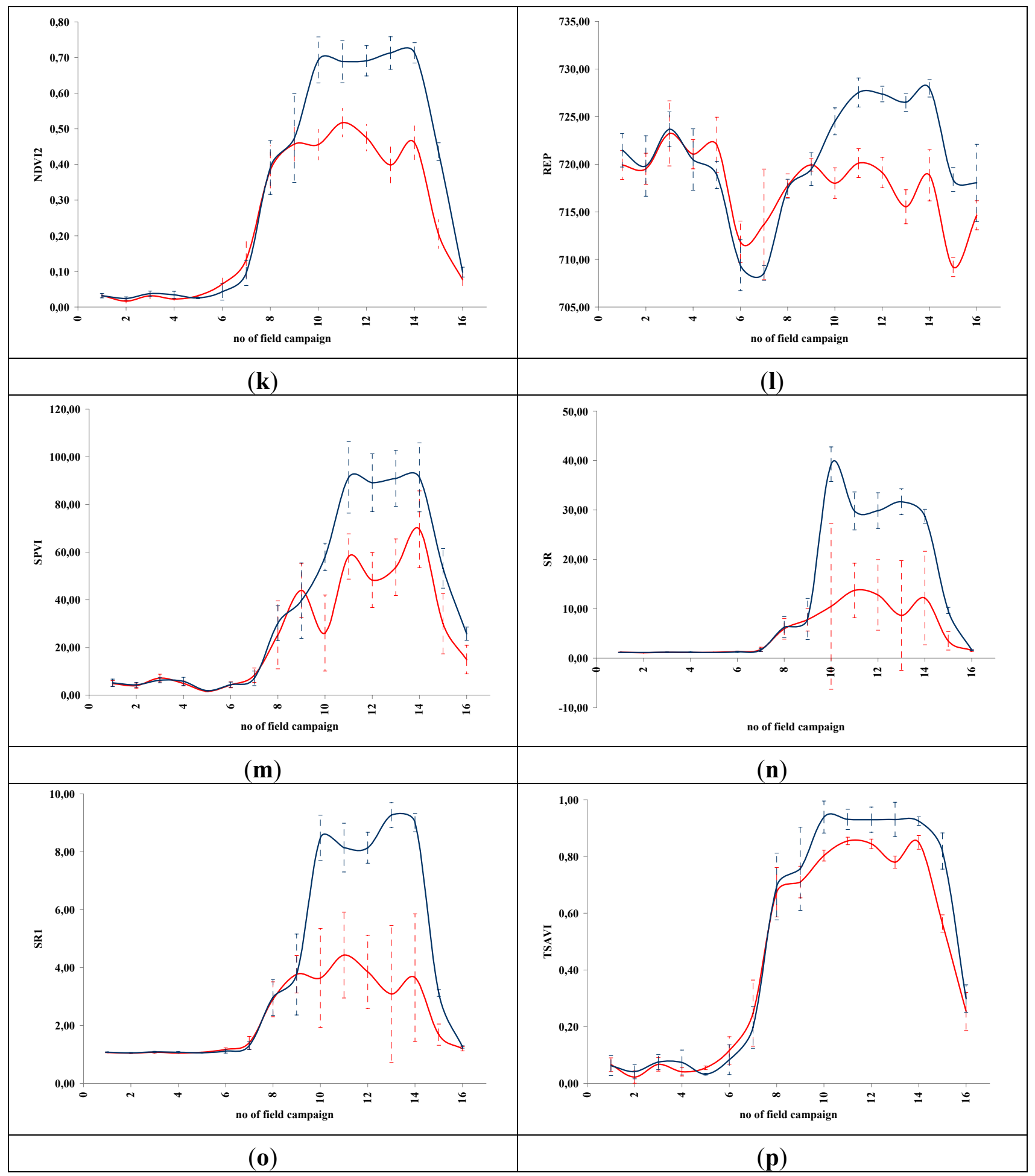


Figure 6. Cont.

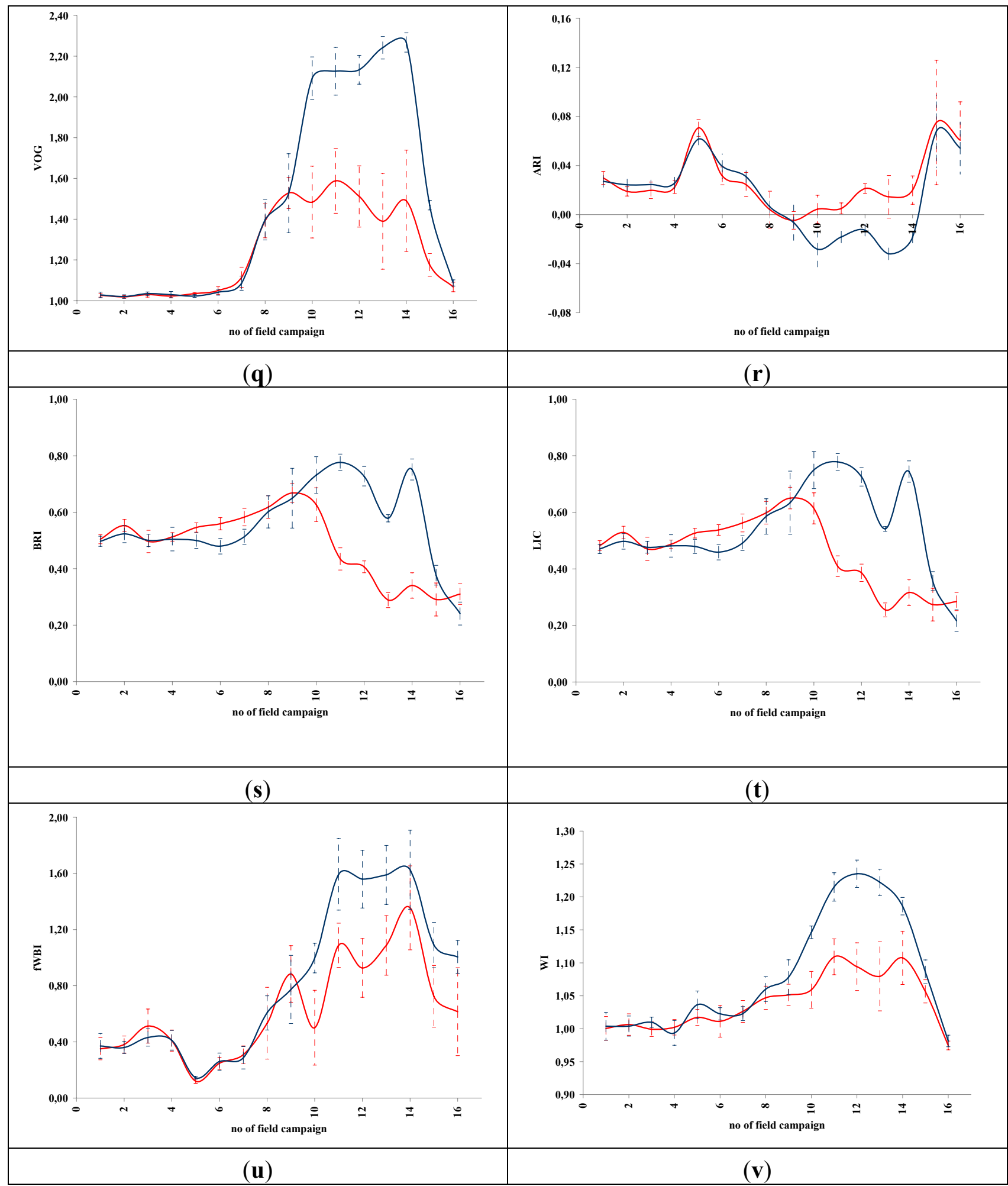

\subsection{Relative Differences of VIs for the Detection of Crop Marks}

For evaluation of the performance of all VIs during the phenological cycle of barley crops, the relative difference in contrast of the measurements between the "archaeological" and nonarchaeological area was examined. The maximum global values for the whole phenological cycle were calculated for "archeological" and non-archaeological areas in order for all indices to have a common 
reference and to be normalized. This is essential, since the absolute values of several VIs are not normalized, while at the same time, several fluctuations may be recorded during the same or different phenological observations. Equation (2) was used in order to calculate the contrast between "archaeological" and non-archaeological areas.

$$
\left[\mathrm{VI} \text { contrast }=\left[\left(\mathrm{VI}_{\text {a.a. }} / \max \mathrm{VI}_{\text {a.a.p.c. }}\right)-\left(\mathrm{VI}_{\text {n.a.a. }} / \max \mathrm{VI}_{\text {n.a.a.p.c. }}\right)\right]^{* 100}\right]
$$

Where:

$\mathrm{VI}_{\text {a.a. }}$ : the VI value over the "archaeological area";

$\max \mathrm{VI}_{\text {a.a....c }}$ : the maximum VI value over the "archaeological area" during the whole phenological cycle;

$\mathrm{VI}_{\text {n.a.a. }}$ : the VI value over the non "archaeological area";

$\max \mathrm{VI}_{\text {n.a.a.p. }}$ : is the maximum $\mathrm{VI}$ value over the non-archaeological area during the whole phenological cycle.

For instance, using Equation (2), the broadband NDVI contrast at 10/17/2011 (no. 1 field campaign) is calculated to $2 \%$. This is based on the phenological observations as follow: $\mathrm{VI}_{\mathrm{a} \text {.a. }}=0.10$, $\max \mathrm{VI}$ a.a.p.c. $=0.93, \mathrm{VI}_{\text {n.a.a. }}=0.10$ and $\max \mathrm{VI}_{\text {n.a.a.p.c. }}=0.82$.

Based on the above formula, the following results were extracted for broadband and narrowband indices, respectively (Tables 2-5). Examining the results from the broadband VIs (Table 2), it was found that the contrast is maximized for all indices when the crop begins to grow (from the end of December until the end of March). The differences occurring range to around 20\%, with some minor exceptions (e.g., Simple Ratio x Normalized Difference Vegetation Index with 86\% difference, no. 18 in Table 2). It is very interesting to note that the SARVI index (no. 15 in Table 2), which is developed in order to minimize both atmospheric and soil background noise, has indicated a high performance $(>50 \%)$. This high performance was noticed during the whole period when the crops were photosynthesizing. SARVI can be, therefore, used for the detection of crop marks in a more systematic way, compared with other indices, which are widely used until now, such as NDVI (no. 3 in Table 2), with only $19 \%$ for a single phenological stage. Moreover, SARVI seems to be the most suitable broadband index for the period of October-November, when the crops have just begun to grown. Furthermore, Table 2 demonstrates that even simple VIs, such as the SR (no. 4 in Table 2), can be also applied with a high performance. The PVI index (no. 9 in Table 2) is also another broadband worthy to being noted, since a relative contrast of $\approx 20 \%$ was found, which lasted for more than three months.

Regarding the narrowband indices (Tables 3-5), the results are quite different. As it was proven, the period for maximizing the VI performance may vary. This is true, since each index is developed in order to monitor specific characteristics of the crops. Therefore, each narrowband index is expected to be maximized when the particular characteristics of the plants occur.

The $\mathbf{S R}_{\mathbf{7 0 5}}, \mathbf{m S R 3}$ and MTCI indices (no. 25, 29 and 31, respectively, in Table 3) show some noticeable characteristics regarding their potential for supporting remote sensing applications during the whole period. Relative high contrast values were recorded from nearly the whole phenological cycle. It is worth noting that this observation was made only to one broadband index (SR, no. 15 in Table 2). The contrast for these three hyperspectral indices is nearly more than $15 \%$, while their highest relative contrast was found to be $43 \%, 55 \%$ and $60 \%$, respectively. The most interesting observation regarding these values is the fact that they were observed during the same phenological 
stage (12/20/2011). This period corresponds to the early beginning of the full greenness of the plants. In general, all indices shown in Table 3 appear to follow different patterns.

Table 2. VI performance for each broadband index (1-18 see Table 1) calculated for each field campaign. The higher values for each index are underlined.

\begin{tabular}{ccccccccccccccccccc}
\hline \multicolumn{1}{|c}{ No of VI } & $\mathbf{1}$ & $\mathbf{2}$ & $\mathbf{3}$ & $\mathbf{4}$ & $\mathbf{5}$ & $\mathbf{6}$ & $\mathbf{7}$ & $\mathbf{8}$ & $\mathbf{9}$ & $\mathbf{1 0}$ & $\mathbf{1 1}$ & $\mathbf{1 2}$ & $\mathbf{1 3}$ & $\mathbf{1 4}$ & $\mathbf{1 5}$ & $\mathbf{1 6}$ & $\mathbf{1 7}$ & $\mathbf{1 8}$ \\
\hline $17 / 10 / 2011$ & 2 & 5 & 2 & 7 & 1 & 1 & 1 & 4 & 0 & 3 & 0 & 1 & 1 & 0 & 46 & 2 & 1 & 0 \\
$26 / 10 / 2011$ & 0 & 0 & 1 & 7 & 13 & 2 & 0 & 2 & 2 & 0 & 3 & 2 & 3 & 0 & 47 & 1 & 0 & 0 \\
$31 / 10 / 2011$ & 1 & 4 & 1 & 7 & 21 & 2 & 2 & 5 & 1 & 2 & 1 & 0 & 3 & 0 & 37 & 1 & 3 & 0 \\
$9 / 11 / 2011$ & 1 & 0 & 2 & 7 & 10 & 0 & 1 & 4 & 2 & 2 & 4 & 4 & 5 & 0 & 44 & 2 & 0 & 0 \\
$16 / 11 / 2011$ & 4 & 5 & 3 & 7 & 5 & 1 & 1 & 3 & 0 & 6 & 2 & 4 & 2 & 0 & 44 & 3 & 0 & 0 \\
$23 / 11 / 2011$ & 7 & 3 & 4 & 8 & 2 & 13 & 3 & 1 & 1 & 7 & 4 & 5 & 5 & 0 & 10 & 4 & 1 & 0 \\
$28 / 11 / 2011$ & 13 & 9 & 9 & 11 & 0 & 13 & 6 & 0 & 4 & 10 & 9 & 10 & 11 & 1 & 34 & 9 & 4 & 0 \\
$13 / 12 / 2011$ & 13 & 12 & 7 & 30 & 2 & 4 & 6 & 4 & 3 & 1 & 7 & 4 & 12 & 6 & $\underline{\mathbf{5 8}}$ & 7 & 3 & $\underline{\mathbf{8 6}}$ \\
$20 / 12 / 2011$ & 11 & $\underline{\mathbf{1 2}}$ & 5 & $\underline{\mathbf{4 1}}$ & 8 & 8 & 15 & 7 & 19 & 3 & 5 & 2 & 10 & 31 & 57 & 5 & 19 & 12 \\
$3 / 1 / 2012$ & 0 & 8 & 5 & 21 & 5 & 0 & $\underline{\mathbf{2 0}}$ & 14 & $\underline{\mathbf{2 6}}$ & 10 & 6 & 3 & 3 & 28 & 56 & 6 & 26 & 5 \\
$11 / 2 / 2012$ & 6 & 2 & 1 & 20 & 6 & 2 & 8 & 10 & 16 & 6 & 1 & 1 & 2 & 4 & 56 & 1 & 16 & 4 \\
$21 / 2 / 2012$ & 8 & 1 & 0 & 14 & 5 & 2 & 15 & 10 & 28 & 7 & 0 & 0 & 0 & 24 & 56 & 0 & $\underline{\mathbf{2 8}}$ & 6 \\
$4 / 3 / 2012$ & 22 & 11 & 9 & 21 & 17 & 5 & 16 & 16 & 24 & 12 & 10 & 6 & 16 & $\underline{\mathbf{4 2}}$ & 56 & 10 & 23 & 5 \\
$17 / 3 / 2012$ & 11 & 0 & 0 & 7 & 10 & 3 & 0 & 9 & 0 & 7 & 0 & 0 & 2 & 8 & 57 & 0 & 0 & 71 \\
$29 / 3 / 2012$ & $\mathbf{3 1}$ & 4 & $\underline{\mathbf{1 9}}$ & 1 & 20 & $\underline{\mathbf{2 1}}$ & 18 & $\underline{\mathbf{2 8}}$ & 19 & $\underline{\mathbf{2 0}}$ & $\underline{\mathbf{2 1}}$ & $\underline{\mathbf{1 4}}$ & $\underline{\mathbf{2 8}}$ & 7 & 56 & $\underline{\mathbf{1 9}}$ & 17 & 25 \\
$17 / 4 / 2012$ & 2 & 3 & 1 & 10 & $\underline{\mathbf{2 9}}$ & 4 & 4 & 0 & 5 & 4 & 3 & 2 & 1 & 1 & 0 & 1 & 7 & 1 \\
\hline
\end{tabular}

Table 3. VI performance for each narrowband index (19-36 see Table 1) calculated for each field campaign. The higher values for each index are underlined.

\begin{tabular}{ccccccccccccccccccc}
\hline \multicolumn{1}{|c}{ No of VI I } & $\mathbf{1 9}$ & $\mathbf{2 0}$ & $\mathbf{2 1}$ & $\mathbf{2 2}$ & $\mathbf{2 3}$ & $\mathbf{2 4}$ & $\mathbf{2 5}$ & $\mathbf{2 6}$ & $\mathbf{2 7}$ & $\mathbf{2 8}$ & $\mathbf{2 9}$ & $\mathbf{3 0}$ & $\mathbf{3 1}$ & $\mathbf{3 2}$ & $\mathbf{3 3}$ & $\mathbf{3 4}$ & $\mathbf{3 5}$ & $\mathbf{3 6}$ \\
\hline $17 / 10 / 2011$ & 3 & 11 & 7 & 0 & 0 & 2 & 16 & 3 & 1 & 0 & 16 & 2 & 35 & 0 & 1 & 2 & 1 & 1 \\
$26 / 10 / 2011$ & 5 & 12 & 4 & 0 & 1 & 1 & 15 & 0 & 2 & 0 & 15 & 1 & 32 & 1 & 1 & 0 & 1 & 0 \\
$31 / 10 / 2011$ & 11 & 11 & 9 & 0 & 1 & 1 & 16 & 1 & 0 & 0 & 16 & 2 & 39 & 1 & 0 & 1 & 0 & 2 \\
$9 / 11 / 2011$ & 2 & 11 & 7 & 1 & 2 & 4 & 15 & 1 & 3 & 0 & 15 & 1 & 42 & 2 & 2 & 0 & 2 & 1 \\
$16 / 11 / 2011$ & 4 & 12 & 5 & 0 & 0 & 4 & 16 & 5 & 3 & 0 & 17 & 2 & 37 & 0 & 2 & 3 & 2 & 1 \\
$23 / 11 / 2011$ & 3 & 14 & 4 & 0 & 2 & 9 & 18 & 12 & 5 & 0 & 20 & 4 & 23 & 2 & 4 & 6 & 4 & 3 \\
$28 / 11 / 2011$ & 1 & 15 & 4 & 0 & 4 & 13 & 21 & 20 & 9 & 0 & 25 & 8 & 30 & 4 & 8 & 12 & 8 & 6 \\
$13 / 12 / 2011$ & 6 & 24 & 12 & 13 & 1 & 2 & 34 & 23 & 3 & 2 & 41 & 25 & 41 & 1 & 6 & 19 & 6 & 5 \\
$20 / 12 / 2011$ & 5 & 24 & 8 & 8 & 16 & 0 & $\underline{\mathbf{4 3}}$ & $\underline{\mathbf{2 6}}$ & 1 & 3 & $\underline{\mathbf{5 5}}$ & $\underline{\mathbf{2 9}}$ & $\underline{\mathbf{6 0}}$ & 16 & 3 & 22 & 3 & 14 \\
$3 / 1 / 2012$ & 7 & 6 & 5 & 32 & 25 & 0 & 6 & 2 & 3 & 75 & 3 & 15 & 1 & 25 & 5 & 9 & 5 & $\underline{\mathbf{1 9}}$ \\
$11 / 2 / 2012$ & 9 & 23 & 11 & 9 & 16 & 3 & 10 & 3 & 1 & 10 & 9 & 14 & 9 & 16 & 1 & 3 & 1 & 8 \\
$21 / 2 / 2012$ & 10 & 19 & 8 & 3 & $\underline{\mathbf{2 7}}$ & 3 & 1 & 4 & 0 & $\underline{\mathbf{1 0 0}}$ & 2 & 10 & 6 & $\underline{\mathbf{2 7}}$ & 0 & 5 & 0 & 15 \\
$4 / 3 / 2012$ & 40 & 4 & 7 & 19 & 20 & 9 & 27 & 21 & 5 & 14 & 24 & 15 & 35 & 20 & 8 & $\underline{\mathbf{2 3}}$ & 8 & 15 \\
$17 / 3 / 2012$ & $\underline{\mathbf{5 1}}$ & $\underline{\mathbf{2 5}}$ & 13 & 45 & 2 & 4 & 15 & 12 & 0 & 14 & 20 & 10 & 26 & 2 & 1 & 11 & 1 & 1 \\
$29 / 3 / 2012$ & 4 & 2 & $\underline{\mathbf{1 6}}$ & $\mathbf{4 8}$ & 21 & $\underline{\mathbf{2 2}}$ & 6 & 20 & $\underline{\mathbf{1 4}}$ & 2 & 8 & 8 & 4 & 21 & $\underline{\mathbf{2 0}}$ & 21 & $\underline{\mathbf{2 0}}$ & 18 \\
$17 / 4 / 2012$ & 34 & 10 & 10 & 3 & 2 & 0 & 17 & 3 & 2 & 0 & 17 & 4 & 24 & 2 & 1 & 1 & 1 & 3 \\
\hline
\end{tabular}


Once again, several SR indices proved to be very promising (see no. 42-46 in Table 4). A generally high relative contrast between the "archaeological" and non-archaeological area is recorded for the whole phenological cycle. A contrast of $44 \%$ was reported using such simple equations as the SR formulas. Nevertheless, SR should be applied in satellite images only after all pre-processing steps have been carried out. Special attention should also be given to radiometric and atmospheric correction of the images used for the detection of crop marks, since SR is expected to be more vulnerable to such errors. Moreover, VOG and $\mathbf{V O G}_{\mathbf{2}}$ (no. 50 and 51, respectively in Table 4) are some narrowband indices that were able to distinguish crop marks with the surrounding area. VOG and SR indices seem to be able to enhance crop marks better during the early stage of their formation (the period OctoberNovember).

Finally, the results from Table 5 show that the use of the visible part of the spectrum is found to be suitable for the detection of crop marks. Indeed, the BRI index (no. 55 in Table 5) generated some interesting high-contrast values without the exploitation of the VNIR part of the spectrum, which is usually used for monitoring vegetation. Using such indices, the available data for monitoring crop marks can be further expanded, not only to the VNIR sensors, but also to some traditional aerial photographs, which are used on the visible part of the spectrum. Some other special indices (NPCI and NPQI, no. 60 and 61 in Table 5, respectively) are also suitable, especially during the period that the crops are fully grown. The latest index (i.e., NPQI) also explores the visible part of the spectrum. The contrast during this period can reach up to $68 \%$. The LIC index (no, 59 in Table 5) seems to give same contrast $(\approx 20 \%)$ for the period October-November, as the VOG index (see no. 50 Table 4 ).

Table 4. VI performance for each narrowband index (37-54 see Table 1) calculated for each field campaign. The higher values for each index are underlined.

\begin{tabular}{ccccccccccccccccccc}
\hline Nate of VI & $\mathbf{3 7}$ & $\mathbf{3 8}$ & $\mathbf{3 9}$ & $\mathbf{4 0}$ & $\mathbf{4 1}$ & $\mathbf{4 2}$ & $\mathbf{4 3}$ & $\mathbf{4 4}$ & $\mathbf{4 5}$ & $\mathbf{4 6}$ & $\mathbf{4 7}$ & $\mathbf{4 8}$ & $\mathbf{4 9}$ & $\mathbf{5 0}$ & $\mathbf{5 1}$ & $\mathbf{5 2}$ & $\mathbf{5 3}$ & $\mathbf{5 4}$ \\
\hline $17 / 10 / 2011$ & 0 & 13 & 14 & 14 & 1 & 6 & 13 & 7 & 14 & 6 & 1 & 1 & 0 & 19 & 3 & 0 & 5 & 1 \\
$26 / 10 / 2011$ & 1 & 0 & 0 & 0 & 1 & 5 & 12 & 7 & 12 & 4 & 0 & 2 & 1 & 19 & 1 & 11 & 1 & 1 \\
$31 / 10 / 2011$ & 1 & 7 & 5 & 5 & 3 & 6 & 13 & 7 & 13 & 6 & 0 & 0 & 1 & 19 & 4 & 10 & 4 & 4 \\
$9 / 11 / 2011$ & 1 & 15 & 20 & 20 & 1 & 5 & 12 & 7 & 12 & 6 & 2 & 3 & 1 & 19 & 3 & 8 & 2 & 4 \\
$16 / 11 / 2011$ & $\mathbf{1}$ & $\underline{\mathbf{2 8}}$ & $\underline{\mathbf{3 0}}$ & $\underline{\mathbf{3 0}}$ & 0 & 6 & 13 & 7 & 13 & 4 & 1 & 3 & 0 & 20 & 6 & 3 & 3 & 3 \\
$23 / 11 / 2011$ & 1 & 22 & 23 & 23 & 1 & 7 & 14 & 8 & 13 & 1 & 0 & 5 & 2 & 20 & 6 & 16 & 2 & 2 \\
$28 / 11 / 2011$ & 1 & 19 & 15 & 15 & 4 & 9 & 18 & 11 & 16 & 1 & 3 & 8 & 4 & 22 & 12 & 13 & 1 & 2 \\
$13 / 12 / 2011$ & 1 & 4 & 3 & 3 & 3 & 27 & 33 & 29 & 27 & 5 & 29 & 5 & 1 & 26 & 38 & 4 & 2 & 1 \\
$20 / 12 / 2011$ & 1 & 3 & 2 & 2 & 20 & $\underline{\mathbf{3 7}}$ & $\underline{\mathbf{4 4}}$ & $\underline{\mathbf{4 0}}$ & $\underline{\mathbf{3 3}}$ & 7 & 22 & 2 & 16 & $\underline{\mathbf{2 9}}$ & $\underline{\mathbf{5 9}}$ & 3 & 2 & 4 \\
$3 / 1 / 2012$ & 0 & 3 & 2 & 2 & 26 & 24 & 9 & 22 & 12 & 12 & 26 & 6 & $\underline{\mathbf{2 5}}$ & 1 & 1 & $\underline{\mathbf{3 6}}$ & 42 & 10 \\
$11 / 2 / 2012$ & 0 & 2 & 2 & 2 & 16 & 24 & 12 & 15 & 12 & 7 & 23 & 1 & 12 & 6 & 12 & 20 & 41 & 13 \\
$21 / 2 / 2012$ & 0 & 2 & 2 & 2 & $\underline{\mathbf{2 8}}$ & 17 & 1 & 5 & 6 & 8 & 25 & 0 & 24 & 1 & 6 & 10 & 5 & 11 \\
$4 / 3 / 2012$ & 1 & 1 & 1 & 1 & 22 & 18 & 30 & 27 & 14 & 13 & 1 & 8 & 15 & 11 & 42 & 28 & $\underline{\mathbf{5 4}}$ & 7 \\
$17 / 3 / 2012$ & 1 & 2 & 2 & 2 & 0 & 15 & 15 & 3 & 1 & 6 & 15 & 1 & 4 & 6 & 22 & 0 & 5 & $\underline{\mathbf{2 0}}$ \\
$29 / 3 / 2012$ & 1 & 1 & 1 & 1 & 15 & 1 & 4 & 1 & 10 & $\underline{\mathbf{3 0}}$ & $\underline{\mathbf{3 2}}$ & $\underline{\mathbf{2 1}}$ & 21 & 9 & 1 & 0 & 0 & 7 \\
$17 / 4 / 2012$ & 0 & 5 & 5 & 5 & 7 & 7 & 13 & 8 & 17 & 0 & 8 & 2 & 2 & 19 & 9 & 1 & 2 & 11 \\
\hline
\end{tabular}


Table 5. VI performance for each narrowband index (55-71 see Table 1) calculated for each field campaign. The higher values for each index are underlined.

\begin{tabular}{cccccccccccccccccc}
\hline No of VI & $\mathbf{5 5}$ & $\mathbf{5 6}$ & $\mathbf{5 7}$ & $\mathbf{5 8}$ & $\mathbf{5 9}$ & $\mathbf{6 0}$ & $\mathbf{6 1}$ & $\mathbf{6 2}$ & $\mathbf{6 3}$ & $\mathbf{6 4}$ & $\mathbf{6 5}$ & $\mathbf{6 6}$ & $\mathbf{6 7}$ & $\mathbf{6 8}$ & $\mathbf{6 9}$ & $\mathbf{7 0}$ & $\mathbf{7 1}$ \\
\hline $17 / 10 / 2011$ & 11 & 3 & 8 & 1 & 14 & 7 & 1 & 2 & 13 & 2 & $\underline{\mathbf{1 0}}$ & 5 & 11 & 11 & 3 & 9 & 9 \\
$26 / 10 / 2011$ & 15 & 1 & 3 & 1 & 17 & 4 & 2 & 4 & 9 & 1 & 9 & 4 & 11 & 11 & 6 & 9 & 6 \\
$31 / 10 / 2011$ & 10 & 1 & 5 & 1 & 11 & 10 & 0 & 0 & 17 & 8 & 10 & 5 & 11 & 11 & 11 & 8 & 11 \\
$9 / 11 / 2011$ & 12 & 2 & 4 & 1 & 13 & 9 & 2 & 1 & 17 & 7 & 9 & 4 & 11 & 11 & 5 & $\underline{\mathbf{1 0}}$ & 0 \\
$16 / 11 / 2011$ & 17 & 8 & 3 & 0 & 19 & 1 & 0 & 12 & 3 & 6 & 10 & 5 & 12 & 11 & 0 & 8 & 8 \\
$23 / 11 / 2011$ & 22 & 6 & 1 & 0 & 24 & 4 & 5 & 13 & 0 & 16 & 9 & 3 & 13 & 13 & 2 & 8 & 4 \\
$28 / 11 / 2011$ & 21 & 5 & 0 & 0 & 23 & 3 & 4 & 13 & 5 & 13 & 9 & 4 & 16 & 15 & 5 & 10 & 1 \\
$13 / 12 / 2011$ & 15 & 19 & 4 & 3 & 17 & 5 & 4 & 6 & 4 & 3 & 10 & $\underline{\mathbf{6}}$ & $\underline{\mathbf{2 1}}$ & 21 & 2 & 9 & 7 \\
$20 / 12 / 2011$ & 16 & 8 & 6 & 3 & 19 & 6 & 11 & 2 & 5 & 5 & 9 & 5 & 24 & $\underline{\mathbf{2 4}}$ & 18 & 8 & 5 \\
$3 / 1 / 2012$ & 0 & 0 & 12 & 6 & 2 & 3 & 54 & 22 & 40 & 1 & 3 & 3 & 11 & 11 & 24 & 3 & 3 \\
$11 / 2 / 2012$ & 35 & 30 & 9 & 1 & 37 & 47 & 54 & 45 & 14 & 3 & 7 & 1 & 9 & 9 & 18 & 2 & 3 \\
$21 / 2 / 2012$ & 33 & $\underline{\mathbf{3 3}}$ & 10 & 4 & 34 & 55 & $\underline{\mathbf{6 5}}$ & 26 & 10 & 4 & 10 & 2 & 1 & 2 & $\underline{\mathbf{2 7}}$ & 1 & 1 \\
$4 / 3 / 2012$ & 31 & 5 & 15 & 4 & 30 & 67 & 53 & 41 & $\underline{\mathbf{6 8}}$ & 11 & 9 & 1 & 17 & 16 & 17 & 2 & 22 \\
$17 / 3 / 2012$ & $\underline{\mathbf{4 6}}$ & 9 & 10 & $\underline{\mathbf{1 1}}$ & $\underline{\mathbf{4 7}}$ & $\underline{\mathbf{6 8}}$ & 47 & $\underline{\mathbf{5 3}}$ & $\mathbf{5}$ & 6 & 10 & 3 & 6 & 4 & 0 & 4 & 19 \\
$29 / 3 / 2012$ & 5 & 3 & $\underline{\mathbf{3 1}}$ & 4 & 4 & 39 & 13 & 45 & 2 & $\underline{\mathbf{3 3}}$ & 0 & 0 & 2 & 2 & 14 & 7 & 3 \\
$17 / 4 / 2012$ & 15 & 3 & 0 & 0 & 16 & 0 & 0 & 23 & 0 & 0 & 10 & 4 & 11 & 11 & 16 & 8 & $\underline{\mathbf{3 5}}$ \\
\hline
\end{tabular}

In general, the contrast of the "archeological" and non-archaeological area can vary from index to index and according to the period of measurement. Moreover, some narrowband indices seem to be able to enhance the spectral differences of the crop marks better. As it is denoted from Tables $2-5$, the researchers can apply different indices for monitoring crop marks depending on the phenological stage of the crops.

\subsection{VIs Applied in Satellite Imagery for the Detection of Crop Marks}

For the aims of this study, some of the most promising vegetation indices, as found in the previous sub-chapter, were evaluated using multispectral and hyperspectral images. Indeed, both the Landsat TM image (31-07-2009 overpass) and EO-1 HYPERION (03-09-2001) were used for the detection of Neolithic tells at the Thessalian plain, in central Greece. These tells, also known as magoules, are typically low hills, which arise approximately 5-10 $\mathrm{m}$ above the surrounding area. Hundreds of such tells are distributed in the Thessalian plains, which are cultivated systematically with crops [3,9]. Some photos from such magoules are shown in Figure 7.

Figure 8 indicates the results after the application of broadband indices to the Landsat image. As it is demonstrated, all indices used (SARVI, SR and NDVI) for the detection of the Melia 2 site were found very useful for supporting remote sensing applications. The tell is easily recognized through photointerpretation, since both the top and the lower part of the magoula is visible, creating a circle. Figure 8(d) shows that the tell is also visible in pseudo-color images, but not as clear as in the previous images. However, the identification of the tell for other broadband indices, such as EVI or Green NDVI (see Figure 9), was not successful. As it is shown in Figure 9, the detection of the Melia 2 is a difficult task; despite the fact that the satellite image used was the same as the one of Figure 8. 
Figure 7. Photos from two magoules located in the Thessalian plain: (a) Zerelia site and (b) Karatsantagli site.

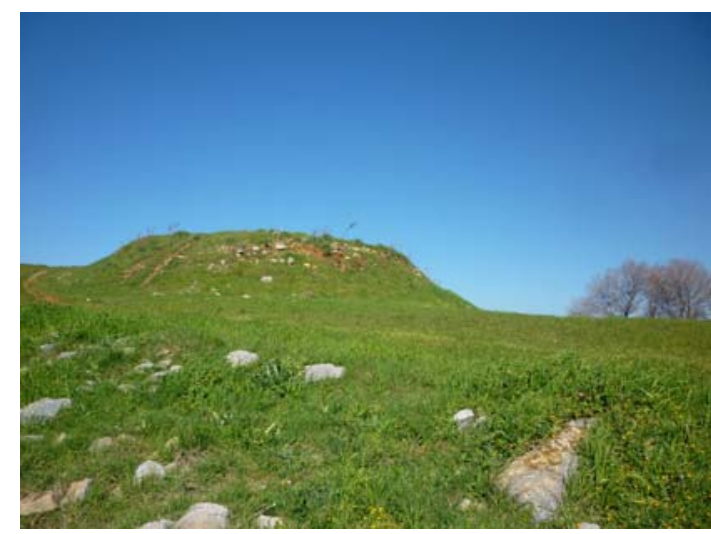

(a)

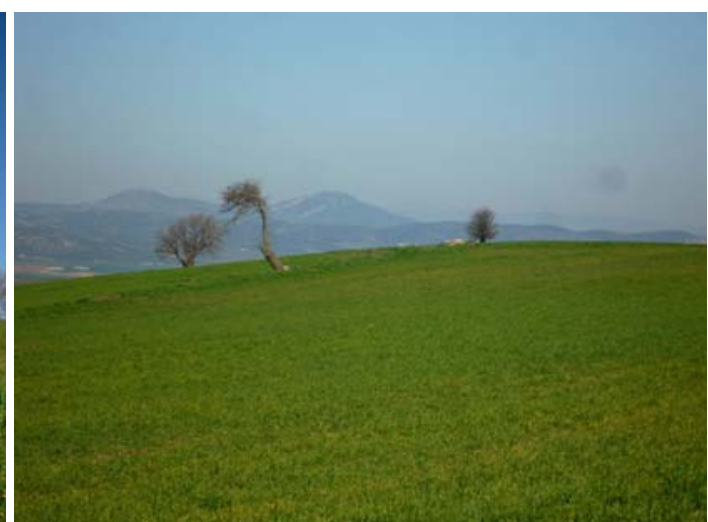

(b)

Figure 8. Landsat multispectral images used for the detection of the neolithic tell Melia 2 (indicated with a red spot) at the Thessalian plain, after the application of broadband indices: (a) SARVI, (b) Simple Ratio, (c) NDVI and (d) pseudo-color VNIR-R-G.

a

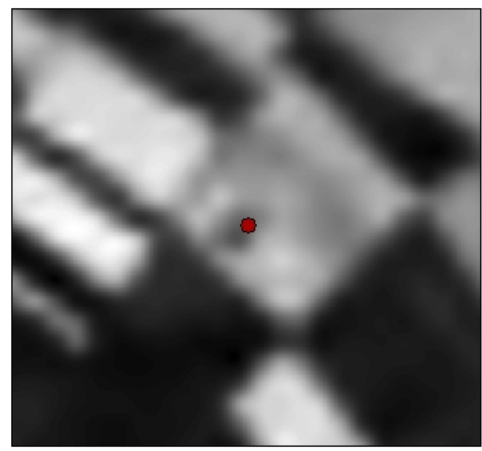

b

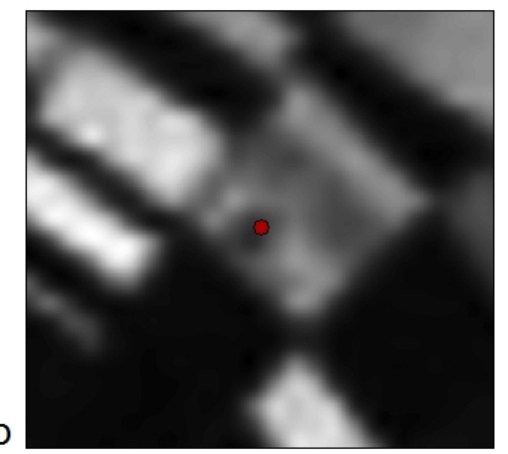

C

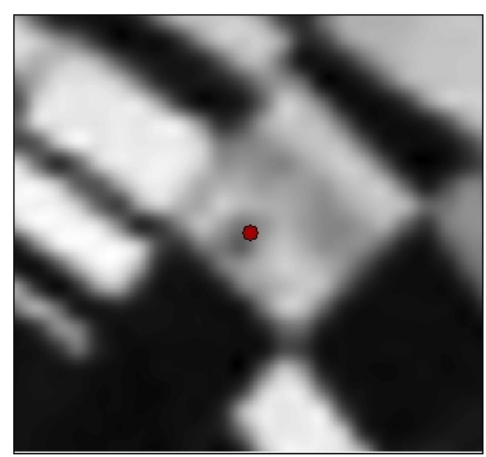

d

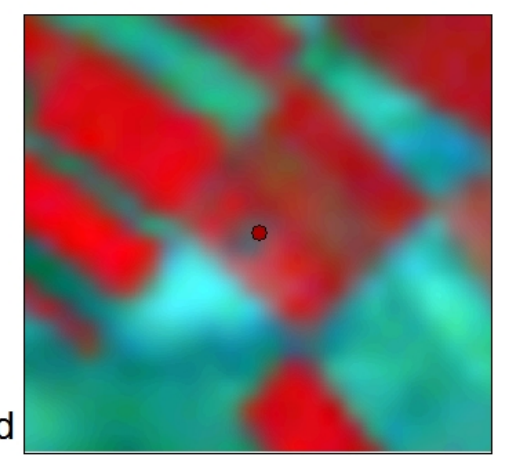


Figure 9. Landsat multispectral images used for the detection of the neolithic tell Melia 2 (indicated with a red spot) at the Thessalian plain, after the application of broadband indices: (a) EVI and (b) Green NDVI.
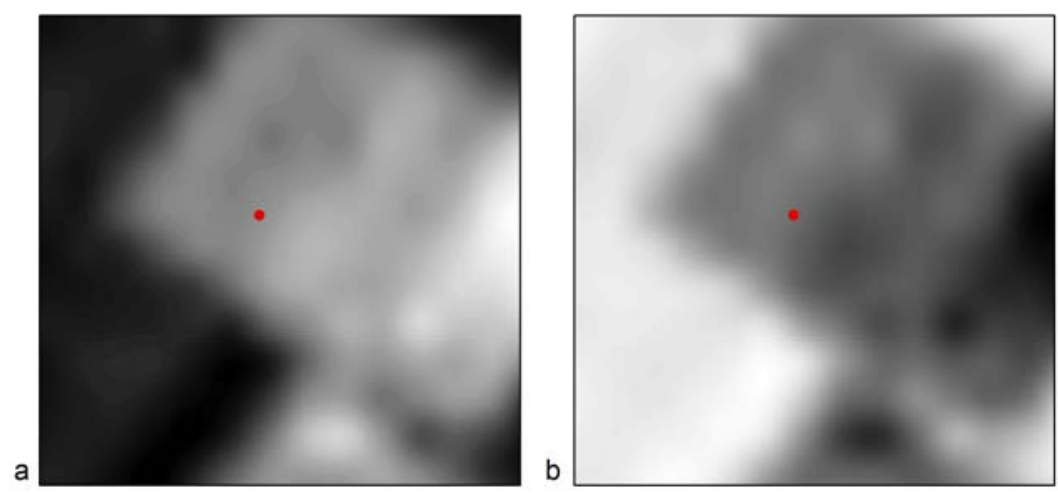

Similarly, Figures 10 and 11 demonstrate the results from the EO-1 HYPERION image. The Neolithic tell is clearly visible in all the narrowband indices used $\left(\mathrm{MSR}_{3}, \mathrm{BRI}, \mathrm{NPCI}, \mathrm{SR}_{705}, \mathrm{SR}\right.$ and $\mathrm{SR}_{1}$ in Figure 10 and $\mathrm{VOG}, \mathrm{SR}_{2}, \mathrm{SR}_{3}, \mathrm{SR}_{4} \mathrm{SR}_{5}$ and $\mathrm{VOG}_{2}$ in Figure 11). These results highlight the fact that more than one vegetation index may be used successfully for the detection of crop marks formed by buried archaeological remains. Hyperspectral indices can be further examined for supporting archaeological results, since their application was found very promising. SR indices, both broadband and narrowband, were able to enhance the contrast of the magoula with its surrounding satisfactorily. Similar results were found with other magoules examined, but are not presented here.

Figure 10. EO-1 HYPERION hyperspectral images used for the detection of the neolithic tell, Melia 2, at the Thessalian plain, after the application of narrowband indices: (a) $\mathrm{MSR}_{3}$, (b) BRI, (c) NPCI, (d) $\mathrm{SR}_{705}$ (e) SR and (f) $\mathrm{SR}_{1}$.

a
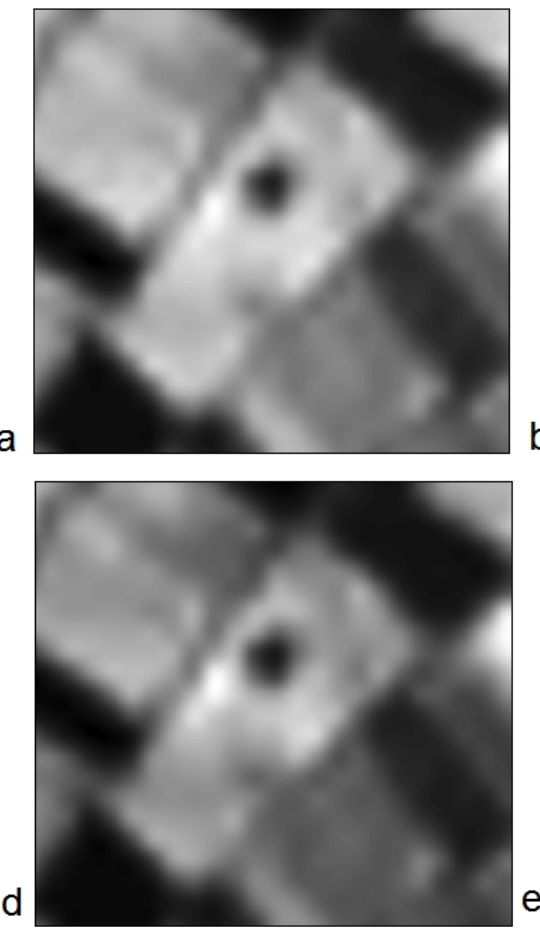
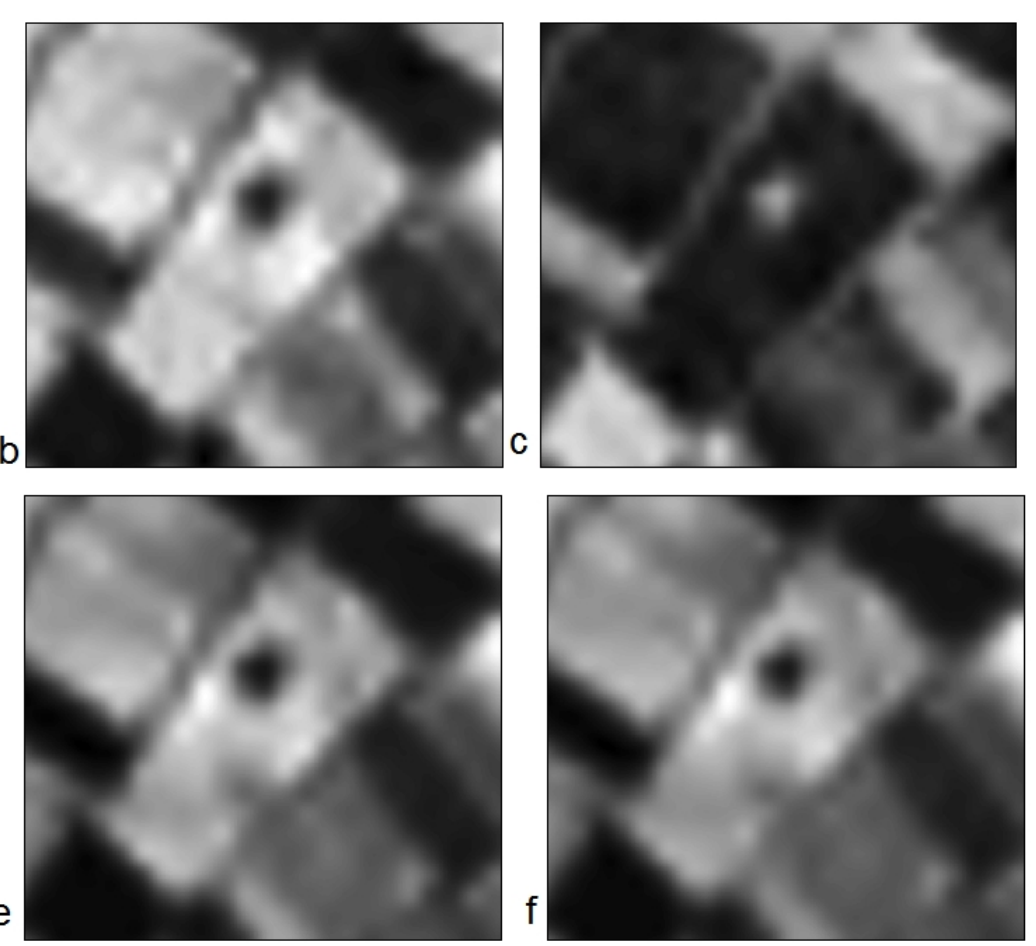
Figure 11. EO-1 HYPERION hyperspectral images used for the detection of the neolithic tell, Melia 2, at the Thessalian plain, after the application of narrowband indices: (a) VOG, (b) $\mathrm{SR}_{2}$, (c) $\mathrm{SR}_{3}$, (d) $\mathrm{SR}_{4}$ (e) $\mathrm{SR}_{5}$ and (f) $\mathrm{VOG}_{2}$.
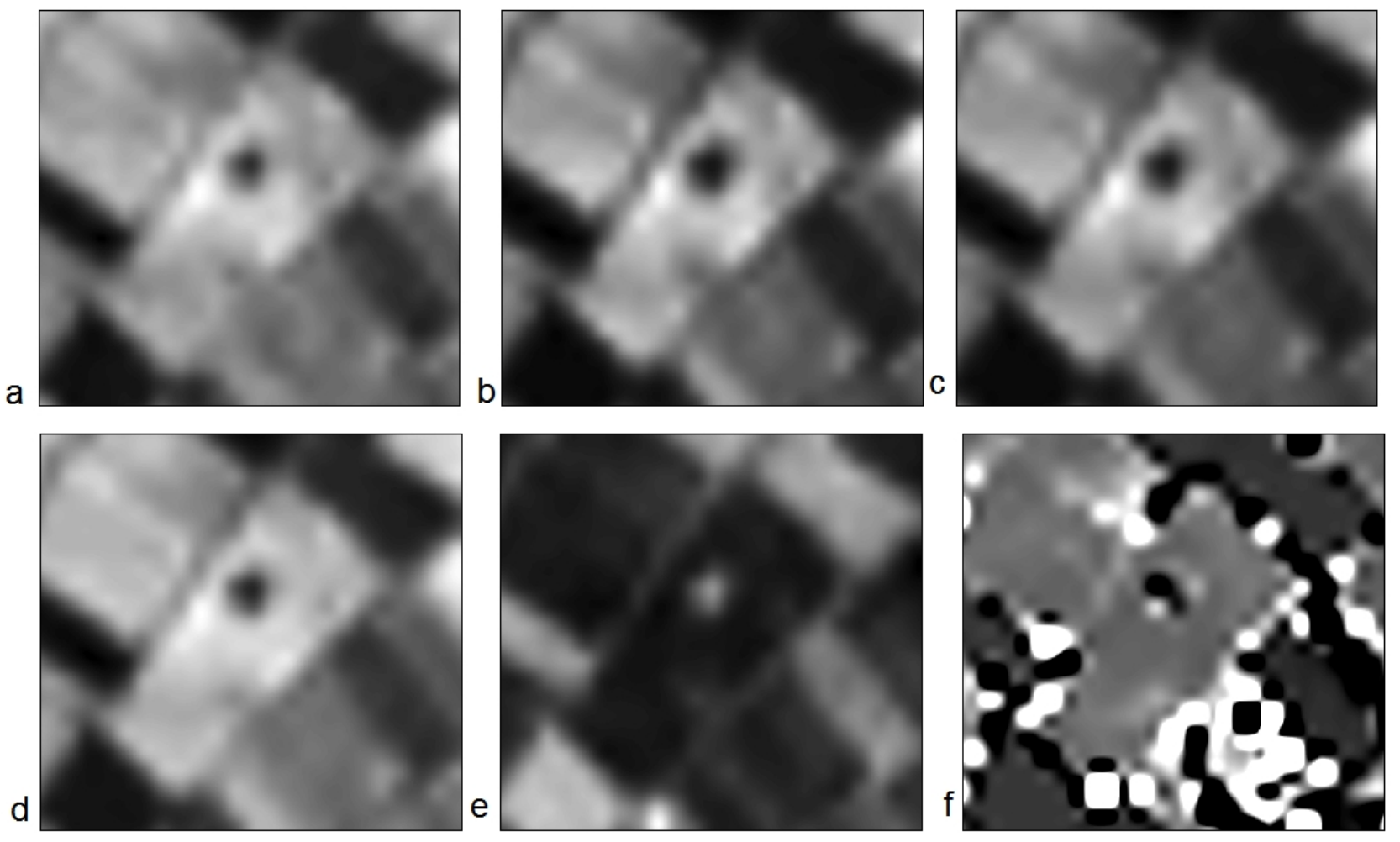

\section{Conclusions}

This study aims to evaluate several Vis, both broadband and narrowband, for monitoring crop marks. Several ground spectroradiometric measurements were collected from a controlled archaeological site at the Alampra village (Cyprus), and different VI values for each campaign were calculated. The results showed that beyond the most widely used VIs in archaeological investigations (e.g., NDVI, SR), several other indices can assist in the detection of crop marks.

Specifically, it was proven that hyperspectral VIs can further maximize the contrast between the archaeological and non-archaeological areas. Compared with the broadband indices, the narrowband indices can maximize the contrast difference up to $20 \%$, with some minor exceptions, especially when crops photosynthesize. Some of the most promising vegetation indices found from this study are the broadband SARVI, SR and PVI, while from the narrowband indices, these are $\mathbf{S R}_{\mathbf{7 0 5}}, \mathbf{m S R} \mathbf{3}, \mathbf{M T C I}$, SR-SR $\mathbf{S}_{\mathbf{6}}$ and VOG.

The above results also applied to multispectral and hyperspectral images for the detection of archaeological remains. This study has highlighted the benefits of the use of hyperspectral images and hyperspectral VIs for supporting archaeological investigations. Indeed, as it was found, only a small number of multispectral VIs have been able to detect neolithic tells, such as SARVI, NDVI and SR, in contrast to several other hyperspectral VIs applied to the Hyperion dataset.

Moreover, VIs based only on the visible part of the spectrum (such as BRI) have also shown some potential use for the detection of crop marks. In this way, a significant amount of data (e.g., traditional 
aerial images in the visible part of the spectrum) can be further exploited in order to assist archaeological research.

The results denoted the fact that for each phenological stage, a different vegetation index may be used in order to enhance the archaeological area of interest compared to a non-archaeological area. Despite that the results may not be similar in a different archaeological environment (i.e., a nonMediterranean region or a different type of crop), the overall outcomes of this study can be applied in any archeological environment. The researchers can select those VIs that better maximize the contrast of the archaeological environment with its surroundings and contribute substantially to the detection of archaeological relics. Further evaluation of such indices will be performed and analyzed using satellite remote sensing data.

The overall results from this study or from similar studies [74-78] can assist in the design of the first satellite sensor intended for archaeological studies. Indeed, the evaluation of ground spectral signatures and VIs over buried archaeological remains, along with the study of the formation of crop marks, can define the spectral regions of the spectrum most suitable for archaeological research.

Recent advantages in the near future regarding hyperspectral spaceborne missions, such as the multi-angular hyperspectral observation capability [79], is one important aspect that needs to be focused on by researchers. Indeed, as [16] highlight, hyperspectral data can be used and exploited in order to find the specific wavebands that are most suitable to study particular biophysical and/or biochemical properties. Such attempts will be performed by the authors for monitoring crop marks.

\section{Acknowledgments}

Thanks are given to the Remote Sensing Laboratory, Department of Civil Eng. \& Geomatics at the Cyprus University of Technology.

\section{References and Notes}

1. Lasaponara, R.; Masini, N. Detection of archaeological crop marks by using satellite QuickBird multispectral imagery. J. Archaeol. Sci. 2007, 34, 214-221.

2 Agapiou, A.; Hadjimitsis, D.G. Vegetation indices and field spectro-radiometric measurements for validation of buried architectural remains: verification under area surveyed with geophysical campaigns. J. Appl. Remote Sens. 2011, 5, 05355.

3 Alexakis, D.; Sarris, A.; Astaras, T.; Albanakis, K. Detection of Neolithic settlements in Thessaly (Greece) through multispectral and hyperspectral satellite imagery. Sensors 2009, 9, 1167-1187.

4 de Laet, V.; Paulissen, E.; Waelkens, M. Methods for the extraction of archaeological features from very high-resolution IKONOS-2 remote sensing imagery, Hisar (southwest Turkey). $J$. Archaeol. Sci. 2007, 34, 830-841.

5 Rowlands, A.; Sarris, A. Detection of exposed and subsurface archaeological remains using multi-sensor remote sensing. J. Archaeol. Sci. 2007, 34, 795-803.

6 Hadjimitsis, D.G.; Themistocleous, K.; Agapiou, A.; Clayton, C.R.I. Multi-temporal study of archaeological sites in Cyprus using atmospheric corrected satellite remotely sensed data. Int. J. Architect. Comput. 2009, 7, 121-138. 
7 Pappu, S.; Akhilesh, K.; Ravindranath, S.; Raj, U. Applications of satellite remote sensing for research and heritage management in Indian prehistory. J. Archaeol. Sci. 2010, 37, 2316-2331.

8 Agapiou, A.; Hadjimitsis, D.G.; Sarris, A.; Themistocleous, K.; Papadavid, G. Hyperspectral ground truth data for the detection of buried architectural remains. Lecture Notes Comput. Sci. 2010, 6436, 318-331.

9 Agapiou, A.; Hadjimitsis, D.G.; Alexakis, D.; Sarris, A. Observatory validation of Neolithic tells ("Magoules") in the Thessalian plain, central Greece, using hyperspectral spectroradiometric data. J. Archaeol. Sci. 2012, 39, 1499-1512.

10 Aqdus, S.A.; Hanson, W.S.; Drummond, J. A Comparative Study for Finding Archaeological Crop Marks Using Airborne Hyperspectral, Multispectral and Digital Photographic Data. In Proceedings of the 2007 Annual Conference of the Remote Sensing and Photogrammetry Society, Newcastle, UK, 12-17 September 2007; pp. 177-182.

11 Lasaponara, R.; Masini, N. Detection of archaeological crop marks by using satellite QuickBird multispectral imagery. J. Archaeol. Sci. 2007, 34, 214-221.

12 Winton, H.; Horne, P. National archives for National Survey Programmes: NMP and the English Heritage Aerial Photograph Collection; Aerial Archaeology Research Group; 2010; Volume 2, pp. 7-18.

13 White, D.C.; Williams, M.; Barr, S.L. Detecting sub-surface soil disturbance using hyperspectral first derivative band rations of associated vegetation stress. Int. Arch. Photogramm. Remote Sens. Spat. Inf. Sci. 2008, XXXVII, 243-248.

14 Stagakis, S.; Markos, N.; Sykioti, O.; Kyparissis, A. Monitoring canopy biophysical and biochemical parameters in ecosystem scale using satellite hyperspectral imagery: An application on a Phlomis fruticosa Mediterranean ecosystem using multiangular CHRIS/PROBA observations. Remote Sens. Environ. 2010, 114, 977-994.

15 Thenkabail, S.P.; Lyon, G.J.; Huete, A. Advances in Hyperspectral Remote Sensing of Vegetation and Agricultural Croplands. In Hyperspectral Remote Sensing of Vegetation; Thenkabail, S.P., Lyon, G.J., Huete, A., Eds.; CRC Press: Boca, Raton, FL, USA, 2011; pp. 3-36.

16 Thenkabail, S.P., Lyon, G.J., Huete, A., Eds. Hyperspectral Remote Sensing of Vegetation; CRC Press: Boca Raton, FL, USA, 2011.

17 Kaimaris, D.; Georgoula, O.; Karadedos, G.; Patias, P. Aerial and Remote Sensing Archaeology in Eastern Macedonia, Greece. In Proceedings of the 22nd CIPA Symposium, Kyoto, Japan, October 2009; pp. 11-15.

18 Hadjimitsis, D.G.; Papadavid, G.; Agapiou, A.; Themistocleous, K.; Hadjimitsis, G.M.; Retalis, A.; Michaelides, S.; Chrysoulakis, N.; Toulios, L.; Clayton, C.R.I. Atmospheric correction for satellite remotely sensed data intended for agricultural applications: Impact on vegetation indices. Nat. Hazards Earth Syst. Sci. 2010, 10, 89-95.

19 Milton, E.J.; Schaepman, M.E.; Anderson, K.; Kneubühler, M.; Fox, N. Progress in field spectroscopy. Remote Sens. Environ. 2009, 113, 92-109.

20 Haboudane, D.; Miller, J.R.; Pattey, E.; Zarco-Tejada, P.; Strachan, I.B. Hyperspectral vegetation indices and novel algorithms for predicting green LAI of crop canopies: Modeling and validation in the context of precision agriculture. Remote Sens. Environ. 2004, 90, 337-352. 
21 Bannari, A.; Morin, D.; Huette, A.R.; Bonn, F. A review of vegetation indices. Remote Sens. Rev. 1995, 13, 95-120.

22 Roberts, A.D.; Roth, L.K.; Perroy, L.R. Hyperspectral Vegetation Indices. In Hyperspectral Remote Sensing of Vegetation; Thenkabail, S.P., Lyon, G.J., Huete, A., Eds.; CRC Press: Boca Raton, FL, USA, 2011; pp. 309-328.

23 Huete, A.R.; Liu, H.Q.; Batchily, K.; van Leeuwen, W. A comparison of vegetation indices over a global set of TM images for EOS-MODIS. Remote Sens. Environ. 1997, 59, 440-451.

24 Gitelson, A. A.; Kaufman, Y. J.; Merzlyak, M. N. Use of a green channel in remote sensing of global vegetation from EOS-MODIS. Remote Sens. Environ. 1996, 58, 289-298.

25 Rouse, J.W.; Haas, R.H.; Schell, J.A.; Deering, D.W.; Harlan, J.C. Monitoring the Vernal Advancements and Retrogradation (Greenwave Effect) of Nature Vegetation; NASA/GSFC Final Report; NASA: Greenbelt, MD, USA, 1974.

26 Jordan, C.F. Derivation of leaf area index from quality of light on the forest floor. Ecology 1969, 50, 663-666.

27 Chen, J.M. Evaluation of vegetation indices and a modified simple ratio for boreal application. Can. J. Remote Sens. 1996, 22, 229-242.

28 Haboudane, D.; Miller, J.R.; Pattey, E.; Zarco-Tejada, P.J.; Strachan, I. Hyperspectral vegetation indices and novel algorithms for predicting green LAI of crop canopies: modeling and validation in the context of precision agriculture. Remote Sens. Environ. 2004, 90, 337-352.

29 Roujean, J.L.; Breon, F.M. Estimating PAR absorbed by vegetation from bidirectional reflectance measurements. Remote Sens. Environ. 1995, 51, 375-384.

30 Gamon, J.A.; Surfus, J.S. Assessing leaf pigment content and activity with a reflectometer. New Phytol. 1999, 143, 105-117.

31 Richardson, A.J.; Wiegand, C.L. Distinguishing vegetation from soil background information. Photogram. Eng. Remote Sensing. 1977, 43, 15-41.

32 Pearson, R.L.; Miller, L.D. Remote Mapping of Standing Crop Biomass and Estimation of the Productivity of the Short Grass Prairie, Pawnee National Grasslands, Colorado. In Proceedings of the 8th International Symposium on Remote Sensing of the Environment, Ann Arbor, MI, USA, 2-6 October 1972; pp. 1357-1381.

33 Baret, F.; Guyot, G. Potentials and limits of vegetation indices for LAI and APAR assessment. Remote Sens. Environ. 1991, 35, 161-173.

34 Qi, J.; Chehbouni, A.; Huete, A.R.; Kerr, Y.H.; Sorooshian, S. A modified soil adjusted vegetation index. Remote Sens. Environ. 1994, 48, 119-126.

35 Kaufman, Y.J.; Tanré, D. Atmospherically resistant vegetation index (ARVI) for EOS-MODIS. IEEE Trans. Geosci. Remote Sens. 1992, 30, 261-270.

36 Pinty, B.; Verstraete, M.M. GEMI: A non-linear index to monitor global vegetation from satellites. Plant Ecol. 1992, 101, 15-20.

37 Rondeaux, G.; Steven, M.; Baret, F. Optimization of soil-adjusted vegetation indices. Remote Sens. Environ. 1996, 55, 95-107.

38 Tucker, C.J. Red and photographic infrared linear combinations for monitoring vegetation. Remote Sens. Environ. 1979, 8, 127-150. 
39 Gong, P.; Pu, R.; Biging, G.S.; Larrieu, M.R. Estimation of forest leaf area index using vegetation indices derived from Hyperion hyperspectral data. IEEE Trans. Geosci. Remote Sens. 2003, 41, 1355-1362.

40 Kim, M.S.; Daughtry, C.S.T.; Chappelle, E.W.; McMurtrey, J.E., III; Walthall, C.L. The Use of High Spectral Resolution Bands for Estimating Absorbed Photosynthetically Active Radiation (APAR). In Proceedings of the 6th Symposium on Physical Measurements and Signatures in Remote Sensing, Val D'Isere, France, 17-21 January 1994.

41 Zarco-Tejada, P.J.; Berjón, A.; López-Lozano, R.; Miller, J.R.; Martín, P.; Cachorro, V.; González, M.R.; de Frutos, A. Assessing vineyard condition with hyperspectral indices: Leaf and canopy reflectance simulation in a row-structured discontinuous canopy. Remote Sens. Environ. 2005, 99, 271-287.

42 Gandia, S.; Fernández, G.; García, J.C.; Moreno, J. Retrieval of Vegetation Biophysical Variables from CHRIS/PROBA Data in the SPARC Campaing. In Proceedings of the 4th ESA CHRIS PROBA Workshop, Frascati, Italy, 28-30 April 2004; pp. 40-48.

43 Daughtry, C.S.T.; Walthall, C.L.; Kim, M.S.; de Colstoun, E.B.; McMurtrey, J.E. Estimating corn leaf chlorophyll concentration from leaf and canopy reflectance. Remote Sens. Environ. 2000, 74, 229-239.

44 Sims, D.A.; Gamon, J.A. Relationships between leaf pigment content and spectral reflectance across a wide range of species, leaf structures and developmental stages. Remote Sens. Environ. 2002, 81, 337-354.

45 Castro-Esau, K.L.; Sánchez-Azofeifa, G.A.; Rivard, B. Comparison of spectral indices obtained using multiple spectroradiometers. Remote Sens. Environ. 2006, 103, 276-288.

46 Chen, J.; Cihlar, J. Retrieving leaf area index of boreal conifer forests using Landsat Thematic Mapper. Remote Sens. Environ. 1996, 55, 153-162

47 Dash, J.; Curran, P.J. The MERIS terrestrial chlorophyll index. Int. J. Remote Sens. 2004, 25, 5403-5413.

48 Gitelson, A.; Merzlyak, M.N. Quantitative estimation of chlorophyll-a using reflectance spectra: Experiments with autumn chestnut and maple leaves. J. Photochem. Photobiol. B: Biol. 1994, 22, 247-252.

49 Roujean, J.L.; Breon, F.M. Estimating PAR absorbed by vegetation from bidirectional reflectance measurements. Remote Sens. Environ. 1995, 51, 375-384.

50 Guyot, G.; Baret, F.; Major, D.J. High spectral resolution: Determination of spectral shifts between the red and near infrared. Int. Arch. Photogramm. Remote Sens. Spat. Inform. Sci. 1988, 27, 750-760.

51 Peñuelas, J.; Filella, I.; Lloret, P.; Munoz, F.; Vilajeliu, M. Reflectance assessment of mite effects on apple trees. Int. J. Remote Sens. 1995, 16, 2727-2733.

52 Penuelas, J.; Baret, F.; Filella, I. Semi-empirical indices to assess carotenoids/chlorophyll-a ratio from leaf spectral reflectance. Photosynthetica 1995, 31, 221-230.

53 Vincini, M.; Frazzi, E.; D’Alessio, P. Angular Dependence of Maize and Sugar Beet Vis from Directional CHRIS/PROBA Data. In Proceedings of the 4th ESA CHRIS PROBA Workshop, Frascati, Italy, 19-21 September 2006; pp. 19-21. 
54 Gitelson, A.A.; Merzlyak, M.N. Remote estimation of chlorophyll content in higher plant leaves. Int. J. Remote Sens. 1997, 18, 2691-2697.

55 Datt, B. Remote sensing of chlorophyll a, chlorophyll b, chlorophyll $\mathrm{a}+\mathrm{b}$, and total carotenoid content in eucalyptus leaves. Remote Sens. Environ. 1998, 66, 111-121.

56 Haboudane, D.; Miller, J.R.; Tremblay, N.; Zarco-Tejada, P.J.; Dextraze, L. Integrated narrow-band vegetation indices for prediction of crop chlorophyll content for application to precision agriculture. Remote Sens. Environ. 2002, 81, 416-426.

57 Broge, N. H.; Leblanc, E. Comparing prediction power and stability of broadband and hyperspectral vegetation indices for estimation of green leaf area index and canopy chlorophyll density. Remote Sens. Environ. 2001, 76, 156-172.

58 Vogelmann, J.E.; Rock, B.N.; Moss, D.M. Red edge spectral measurements from sugar maple leaves. Int. J. Remote Sens. 1993, 14, 1563-1575.

59 Zarco-Tejada, P.J.; Pushnik, J.C.; Dobrowski, S.; Ustin, S.L. Steady-state chlorophyll a fluorescence detection from canopy derivative reflectance and double-peak red-edge effects. Remote Sens. Environ. 2003, 84, 283-294.

60 Gitelson, A.A.; Merzlyak, M.N.; Chivkunova, O.B. Optical properties and nondestructive estimation of anthocyanin content in plant leaves. Photochem. Photobiol. 2001, 74, 38-45.

61 Zarco-Tejada, P.J.; Berjón, A.; López-Lozano, R.; Miller, J.R.; Martín, P.; Cachorro, V.; González, M.R.; de Frutos, A. Assessing vineyard condition with hyperspectral indices: Leaf and canopy reflectance simulation in a row-structured discontinuous canopy. Remote Sens. Environ. 2005, 99, 271-287.

62 Gitelson, A.A.; Zur, Y.; Chivkunova, O.B.; Merzlyak, M.N. Assessing carotenoid content in plant leaves with reflectance spectroscopy. Photochem. Photobiol. 2002, 75, 272-281.

63 Lichtenthaler, H.K.; Lang, M.; Sowinska, M.; Heisel, F.; Miehe, J.A. Detection of vegetation stress via a new high resolution fluorescence imaging system. J. Plant Physiol. 1996, 148, 599-612.

64 Peñuelas, J.; Gamon, J.A.; Fredeen, A.L.; Merino, J.; Field, C.B. Reflectance indices associated with physiological changes in nitrogen- and water-limited sunflower leaves. Remote Sens. Environ. 1994, 48, 135-146.

65 Barnes, J.D.; Balaguer, L.; Manrique, E.; Elvira, S.; Davison, A.W. A reappraisal of the use of DMSO for the extraction and determination of chlorophylls a and $b$ in lichens and higher plants. Environ. Experimental Bot. 1992, 32, 85-100.

66 Gamon, J.A.; Serrano, L.; Surfus, J.S. The photochemical reflectance index: An optical indicator of photosynthetic radiation use efficiency across species, functional types, and nutrient levels. Oecologia 1997, 112, 492-501.

67 Filella, I.; Amaro, T.; Araus, J.L.; Peñuelas, J. Relationship between photosynthetic radiation-use efficiency of barley canopies and the photochemical reflectance index (PRI). Physiologia Plantarum 1996, 96, 211-216.

68 Merzlyak, M.N.; Gitelson, A.A.; Chivkunova, O.B.; Rakitin, V.Y. Nondestructive optical detection of pigment changes during leaf senescence and fruit ripening. Physiologia Plantarum 1999, 106, 135-141.

69 Peñuelas, J.; Filella, I.; Biel, C.; Serrano, L.; Savé, R. The reflectance at the 950-970 nm region as an indicator of plant water status. Int. J. Remote Sens. 1993, 14, 1887-1905. 
70 Agapiou, A.; Hadjimitsis, G.D.; Georgopoulos, A.; Sarris, A.; Alexakis, D.D. Towards to an archaeological index: Identify the spectral regions of stress vegetation due to buried archaeological remain. Lecture Notes Comput. Sci. 2012, 7616, 129-138.

71 Agapiou, A.; Hadjimitsis, G.D.; Sarris, A.; Georgopoulos, A. A New Method for the Detection of Architectural Remains Using Field Spectroscopy: Experimental Remote Sensing Archaeology. In Proceedings of the XVI Congress of the UISPP, Florianopolil, Brazil, 4-10 September 2011.

72 Alexakis, D.; Agapiou, A.; Hadjimitsis, D.; Sarris, A. Remote Sensing Applications in Archaeological Research. In Remote Sensing-Applications; Escalante, B., Ed.; InTech: Rijeka, Croatia, 2012; pp. 435-462.

73 Wu, X.; Sullivan, T.J.; Heidinger, K.A. Operational calibration of the Advanced Very High Resolution Radiometer (AVHRR) visible and near-infrared channels. Can. J. Remote Sens. 2010, 36, 602-616.

74 Agapiou, A.; Hadjimitsis, G.D.; Sarris, A.; Georgopoulos, A.; Alexakis, D.D. Optimum temporal and spectral window for monitoring crop marks over archaeological remains in the Mediterranean region, J. Archaeol. Sci. 2012, 10.1016/j.jas.2012.10.036.

75 Agapiou, A.; Alexakis, D.D.; Hadjimitsis, G.D. Evaluation of spectral sensitivity of ALOS, ASTER, IKONOS, LANDSAT and SPOT satellite sensors intended for the detection of archaeological crop marks, Int. J. Dig. Earth 2012, doi:10.1080/17538947.2012.674159.

76 Verhoeven, G.; Doneus M. Balancing on the borderline-A low cost approach to visualize the red- edge shift for the benefit of the aerial archaeology. Archaeol. Prospect. 2011, 18, 267-278.

77 Hejcman, M.; Smrž, Z. Cropmarks in stands of cereals, legumes and winter rape indicate sub-soil archaeological features in the agricultural landscape of Central Europe. Agric. Ecosyst. Environ. 2010, 138, 348-354.

78 Gojda, M.; Hejcman, M. Cropmarks in main field crops enable the identification of a wide spectrum of buried features on archaeological sites in Central Europe. J. Archaeol. Sci. 2012, 39, 1655-1664.

79 Qi, J.; Inoue, Y.; Wiangwang, N. Hyperspectral Remote Sensing in Global Change Studies. In Hyperspectral Remote Sensing of Vegetation; Thenkabail, S.P., Lyon, G.J., Huete, A., Eds.; CRC Press: Boca Raton, FL, USA, 2011; pp. 69-90.

(C) 2012 by the authors; licensee MDPI, Basel, Switzerland. This article is an open access article distributed under the terms and conditions of the Creative Commons Attribution license (http://creativecommons.org/licenses/by/3.0/). 